\title{
Loss of IL-15 receptor $\alpha$ alters the endurance, fatigability, and metabolic characteristics of mouse fast skeletal muscles
}

\author{
Emidio E. Pistilli, ${ }^{1}$ Sasha Bogdanovich, ${ }^{1}$ Fleur Garton,, ${ }^{2}$ Nan Yang, ${ }^{2}$ Jason P. Gulbin, ${ }^{3}$ \\ Jennifer D. Conner, ${ }^{4}$ Barbara G. Anderson, ${ }^{4,5}$ LeBris S. Quinn, ${ }^{4,5}$ \\ Kathryn North, ${ }^{2}$ Rexford S. Ahima, ${ }^{6}$ and Tejvir S. Khurana ${ }^{1}$

\begin{abstract}
1Department of Physiology and Pennsylvania Muscle Institute, University of Pennsylvania, Philadelphia, Pennsylvania, USA. 2Institute for Neuroscience and Muscle Research, The Children's Hospital at Westmead, Sydney, New South Wales, Australia. ${ }^{3}$ Australian Institute of Sport (AIS), Canberra, Australia. ${ }^{4}$ Geriatric Research, Education, and Clinical Center,

VA Puget Sound Health Care System, Seattle, Washington, USA. ${ }^{5}$ Division of Gerontology and Geriatric Medicine, Department of Medicine, University of Washington, Seattle, Washington, USA. ${ }^{6}$ Division of Endocrinology, Diabetes, and Metabolism, Department of Medicine, University of Pennsylvania, Philadelphia, Pennsylvania, USA.
\end{abstract}

\begin{abstract}
IL-15 receptor $\alpha(I L-15 R \alpha)$ is a component of the heterotrimeric plasma membrane receptor for the pleiotropic cytokine IL-15. However, IL-15R $\alpha$ is not merely an IL-15 receptor subunit, as mice lacking either IL-15 or IL-15R $\alpha$ have unique phenotypes. IL-15 and IL-15R $\alpha$ have been implicated in muscle phenotypes, but a role in muscle physiology has not been defined. Here, we have shown that loss of IL-15R $\alpha$ induces a functional oxidative shift in fast muscles, substantially increasing fatigue resistance and exercise capacity. IL-15R $\alpha-k n o c k o u t$ (IL-15R $\alpha-\mathrm{KO}$ ) mice ran greater distances and had greater ambulatory activity than controls. Fast muscles displayed fatigue resistance and a slower contractile phenotype. The molecular signature of these muscles included altered markers of mitochondrial biogenesis and calcium homeostasis. Morphologically, fast muscles had a greater number of muscle fibers, smaller fiber areas, and a greater ratio of nuclei to fiber area. The alterations of physiological properties and increased resistance to fatigue in fast muscles are consistent with a shift toward a slower, more oxidative phenotype. Consistent with a conserved functional role in humans, a genetic association was found between a SNP in the IL15RA gene and endurance in athletes stratified by sport. Therefore, we propose that IL-15R $\alpha$ has a role in defining the phenotype of fast skeletal muscles in vivo.
\end{abstract}

\section{Introduction}

IL-15 is a pleiotropic cytokine, with proposed roles in both lymphoid and non-lymphoid tissues. IL-15 was classified as an interleukin based on its 4- $\alpha$-helical secondary structure and its ability to mimic the functions of IL-2 in vitro (1). The plasma membrane receptor for IL-15 was initially characterized as trimeric in structure, composed of IL- 2 receptor $\beta$ (IL-2R $\beta$ ), the common gamma chain $(\gamma c)$, and a specific IL-15R $\alpha$ chain $(2,3)$. Transcripts for IL-15 and IL-15R $\alpha$ have a wide tissue distribution, and skeletal muscle tissue contains an abundance of IL15 and IL15RA mRNAs $(1,2)$ that are responsive to atrophic stimuli (4), muscle contraction (5), and aging $(4,6,7)$. In vitro experiments in myogenic cells initially suggested that IL-15 was an anabolic factor for skeletal muscle, able to stimulate the accumulation of contractile protein in differentiated myotubes (8-10). However, this result has not been replicated in vivo, as increasing IL-15 levels in wild-type experimental animals has not resulted in muscle hypertrophy, suggesting that IL-15 and IL-15R $\alpha$ interactions in vivo may be more complex than simple ligand-receptor binding (11-13). Recently, studies have revealed differing neurological and locomotor activities when comparing IL-15R $\alpha-\mathrm{KO}$, IL-15-KO, and $\operatorname{IL}-2 \mathrm{R} \beta-\mathrm{KO}$ mice $(14,15)$. The data demonstrate that unique roles for IL-15R $\alpha$ and IL-15 in vivo exist, since interruption of IL-15 signaling by deletion of either IL-15 or IL-15R $\alpha$ resulted in dif-

Conflict of interest: The authors have declared that no conflict of interest exists. Citation for this article: J Clin Invest. 2011;121(8):3120-3132. doi:10.1172/JCI44945 fering mouse phenotypes. SNPs in the human IL15 and IL15RA genes have been associated with muscle phenotypes (16), muscle responses to resistance training (17), metabolic syndrome (16), and obesity (18-20), providing additional rationale to support a role for these molecules in muscle.

IL-15 and IL-15R $\alpha$ interactions at the cell membrane can lead to recruitment of IL-2R $\beta$ and $\gamma c$ to form the heterotrimeric receptor, although IL-15 signaling may not occur strictly as the result of a secreted cytokine binding to a cell surface receptor. Intracellular interactions within the Golgi can lead to the formation of a complex between IL-15 and IL-15R $\alpha$, which can either be secreted or anchored to the cell membrane for trans-presentation to neighboring cells displaying IL-2R $\beta$ and $\gamma c$ receptors $(21,22)$. In addition, IL-15R $\alpha$ is not required for IL-15 signaling, as IL-15 can also bind to the low-affinity IL-2R $\beta$ and $\gamma$ cheterodimeric receptor (23). These data suggest that IL-15R $\alpha$ alone should not be considered merely a subunit of the trimeric IL-15 receptor, but is likely an integral binding partner that can alter IL-15 biological activity. Indeed, IL-15/IL-15R $\alpha$ complex formation leads to an increase in biological activity and half-life of IL-15, and this complex has been hypothesized to be the predominant form of the molecule $(21,24-26)$. Mice that lack either IL-15 or IL-15R $\alpha$ have unique phenotypes $(14,15,27,28)$, and multiple isoforms of IL-15R $\alpha$ exist that can either potentiate or inhibit the effects of IL-15 (29-33). Thus, IL-15/IL-15R $\alpha$ interactions and associated signaling are extremely complex, and IL-15R $\alpha$ likely represents a mechanism for controlling IL-15 signaling capacity. 

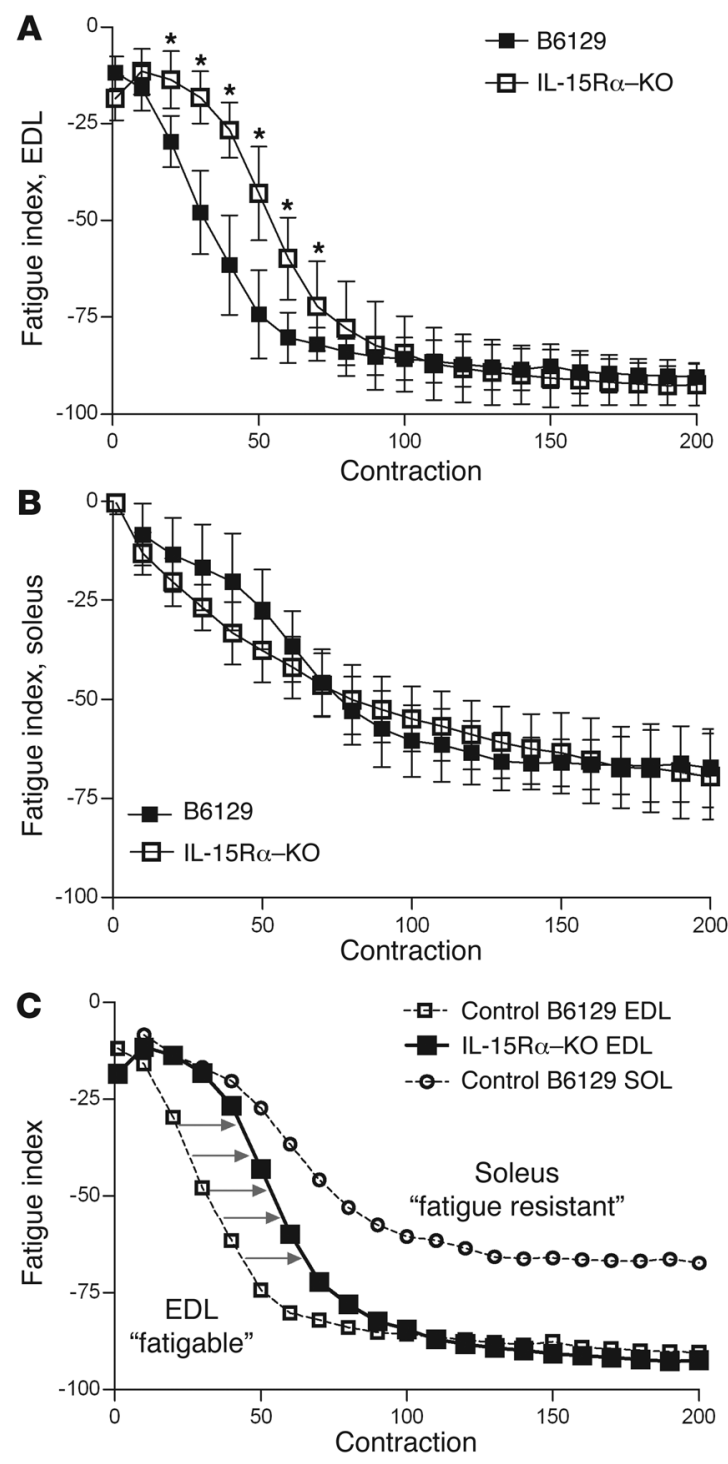

Due to the apparent differential actions of IL-15 and IL-15R $\alpha$, and observations that IL-15R $\alpha$ alters the action of IL-15, we chose to perform studies in multiple mouse strains in which IL-15R $\alpha$ and IL-15 expression was genetically modulated in order to determine a role for these molecules in muscle physiological responses in vivo. We hypothesized that IL-15R $\alpha$ has a role in defining the phenotype of fast skeletal muscles in vivo. Our data demonstrate that loss of IL-15R $\alpha$ results in a remodeling of fast skeletal muscles to a more oxidative phenotype that manifests as a greater exercise capacity and resistance to fatigue in mice due, in part, to adaptations in mitochondria - phenotypes that were only observed in IL-15R $\alpha-\mathrm{KO}$ mice. These findings in murine muscle, coupled with a significant association between a SNP in exon 3 of the IL15RA gene and human endurance athletes, support our hypothesis whereby IL-15R $\alpha$ has a role in defining the phenotype of fast skeletal muscles.

\section{Results}

Fast muscles from $I L-15 R \alpha-K O$ mice adopt a more fatigue-resistant phenotype. Male mice from 3 strains of genetically modified mice were used in these studies, with each strain compared with a spe-

\section{Figure 1}

Fast EDL muscles from IL-15R $\alpha-\mathrm{KO}$ mice adopt a more oxidative, fatigue-resistant phenotype. A repeated stimulation protocol was performed to determine the fatigue characteristics of isolated EDL muscles. Muscles were stimulated for 330 ms every second for 6 minutes, and the fatigue index was calculated as the percent difference in tetanic force between the first contraction and each subsequent contraction. (A) The fatigue curve of EDL muscles from IL-15R $\alpha-\mathrm{KO}$ mice ( $n=8$ muscles) was shifted to the right compared with EDL muscles from B6129 control mice ( $n=8$ muscles), indicating a resistance to repeated stimulation-induced fatigue. (B) No differences were observed in the fatigue index of soleus muscles from IL-15R $\alpha-\mathrm{KO}$ ( $n=8$ muscles) and B6129 control mice ( $n=8$ muscles). (C) The fatigue curve for EDL muscles from IL-15R $\alpha-K O$ mice is plotted with fatigue curves of EDL and soleus muscles from B6129 control mice. The fatigue curve from IL-15R $\alpha-K O$ EDL muscles lies between the curves for the fatigable EDL muscle and the fatigue-resistant soleus muscle, highlighting the oxidative characteristics of EDL muscles deficient in IL-15R $\alpha$. 350 total contractions were analyzed per muscle, with data presented as mean \pm SD. ${ }^{*} P<0.05$.

cific background control strain: IL-15R $\alpha-\mathrm{KO}(n=20)(27)$ and B6129SF2/J (B6129) control $(n=16)$; IL-15-KO $(n=8)(28)$ and BL/6NTac control $(n=8)$; and HSA-IL-15TG $(n=7)$ (34) and HSAIL-15Con control $(n=7)$. The IL- $15 \mathrm{R} \alpha-\mathrm{KO}$ mouse is homozygous null for the IL15RA gene and was originated on a B6129 background (27). Therefore, littermates were not available as controls, and the recommended background strain for IL-15R $\alpha-\mathrm{KO}$ mice, the B6129 mouse, was used. HSA-IL-15TG mice overexpress IL-15 from a skeletal muscle-specific promoter, as previously described (34). The C57BL/6 wild-type mouse $(n=8)$ was used as an additional comparison to these genetic mouse strains, but was not included in any statistical analyses.

To address the fatigue characteristics of isolated skeletal muscles, we dissected the fast extensor digitorum longus (EDL) and slow soleus muscles from anesthetized mice and subjected them to a repeated contraction protocol in which muscles were stimulated for $330 \mathrm{~ms}$ every second for 6 minutes at a stimulation frequency of $40 \mathrm{~Hz}$. The rate of fatigue (i.e., fatigue index) was quantified by calculating the percent difference in force of the initial contraction and every subsequent contraction, with values plotted as fatigue curves. The fatigue curves of fast EDL and slow soleus muscles from IL- $15 \mathrm{R} \alpha-\mathrm{KO}$ mice and their corresponding $\mathrm{B} 6129$ control mice are depicted in Figure 1. The fatigue index curve of EDL muscles from IL-15R $\alpha-\mathrm{KO}$ mice was shifted to the right during the first 70 seconds of the repeated stimulation protocol, demonstrating the maintenance of isometric force with repeated contractions (Figure 1A). No differences were observed in the fatigue curves of soleus muscles from IL-15R $\alpha-\mathrm{KO}$ and B6129 mice (Figure 1B). A plot combining the fatigue curve of EDL muscles from IL-15R $\alpha-\mathrm{KO}$ mice and fatigue curves of EDL and soleus muscles from B6129 control mice reveals a clear shift in fatigue resistance (Figure 1C). Specifically, the initial portions of the fatigue curves (approximately 30-40 seconds) are indistinguishable when comparing the soleus muscle from control mice and the EDL muscle from IL-15R $\alpha-\mathrm{KO}$ mice. The shift in fatigue resistance was significant, but relatively short, as the fatigue curves of EDL muscles from IL-15R $\alpha-\mathrm{KO}$ mice and B6129 control mice are indistinguishable after 70 seconds of the protocol. No differences were observed in the fatigue index curves of EDL or soleus muscles when comparing IL-15-KO mice with BL/6NTac and 
Table 1

Anatomical and physiological properties of EDL muscles from IL-15R $\alpha-K 0$ mice

\section{EDL}

Muscle weight (mg)

Muscle weight/body weight $\mathrm{mg} \bullet \mathrm{g}^{-1}$

CSA $\left(\mathrm{mm}^{2}\right)$

$\mathrm{L}_{0}(\mathrm{~mm})$

Contraction time (ms)

Rate of force development $\left(\mathrm{mN} \bullet \mathrm{s}^{-1}\right)$

$1 / 2$ RT (ms)

Rate of relaxation $\left(\mathrm{mN} \bullet \mathrm{s}^{-1}\right)$

\section{B6129}

$13.6 \pm 1.3$

$0.53 \pm 0.04$

$2.1 \pm 0.2$

$13.1 \pm 0.81$

$38.8 \pm 5.0$

$3254.8 \pm 685.1$

$28.8 \pm 7.2$

$2921.7 \pm 960.9$

\section{IL-15R $\alpha-$ K0}

$13.4 \pm 1.4$

$0.59 \pm 0.04^{\mathrm{A}}$

$2.3 \pm 0.3$

$12.4 \pm 0.61$

$37.4 \pm 5.4$

$2410.3 \pm 767.6^{\mathrm{B}}$

$32.2 \pm 7.4$

$1753.7 \pm 778.5^{\mathrm{A}}$

Data are presented as mean $\pm \mathrm{SD} .{ }^{A} P<0.0001,{ }^{B} P<0.001$.

HSA-IL-15TG with HSA-IL-15Con control mice (Supplemental Figure 1; supplemental material available online with this article; doi:10.1172/JCI44945DS1). These data provide physiological evidence that loss of IL-15R $\alpha$ initiates muscle remodeling, whereby the fast EDL muscle displays a more fatigue-resistant phenotype, which was not observed in fast muscles from IL-15-KO mice or HSA-IL-15TG mice.
Isometric contractile properties of fast muscles from IL-15R $\alpha-K O$ mice display a slower contractile phenotype. Fast EDL and slow soleus muscles from all mouse strains were dissected and transferred to oxygenated Ringer's solution for assessment of isometric forcegenerating capacity ex vivo. Isometric twitch and tetanic contractions were performed using a stimulator and a force transducer to quantify the maximum contractile forces, as well as parameters related to the speed of contraction and speed of relaxation of dissected muscles. No differences were observed in the wet weight or whole muscle cross-sectional area (CSA) of the EDL muscles from IL-15R $\alpha-\mathrm{KO}$ and B6129 control mice (Table 1). Absolute force production during twitch and tetanic contractions was $27.1 \%$ and $18.2 \%$ less, respectively, in EDL muscles from IL-15R $\alpha-\mathrm{KO}$ mice compared with B6129 control mice (Figure 2, A, B, D, and E). When forces were normalized to muscle CSA to obtain specific force (i.e., $\mathrm{mN} \cdot \mathrm{mm}^{-2}$ ), twitch force was $33.9 \%$ less and tetanus force was $24.9 \%$ less in EDL muscles from IL-15R $\alpha-\mathrm{KO}$ mice compared with B6129 control mice (Figure 2, C and F). The twitch/tetanus ratio, an indirect measure of the motor unit composition of a muscle, was
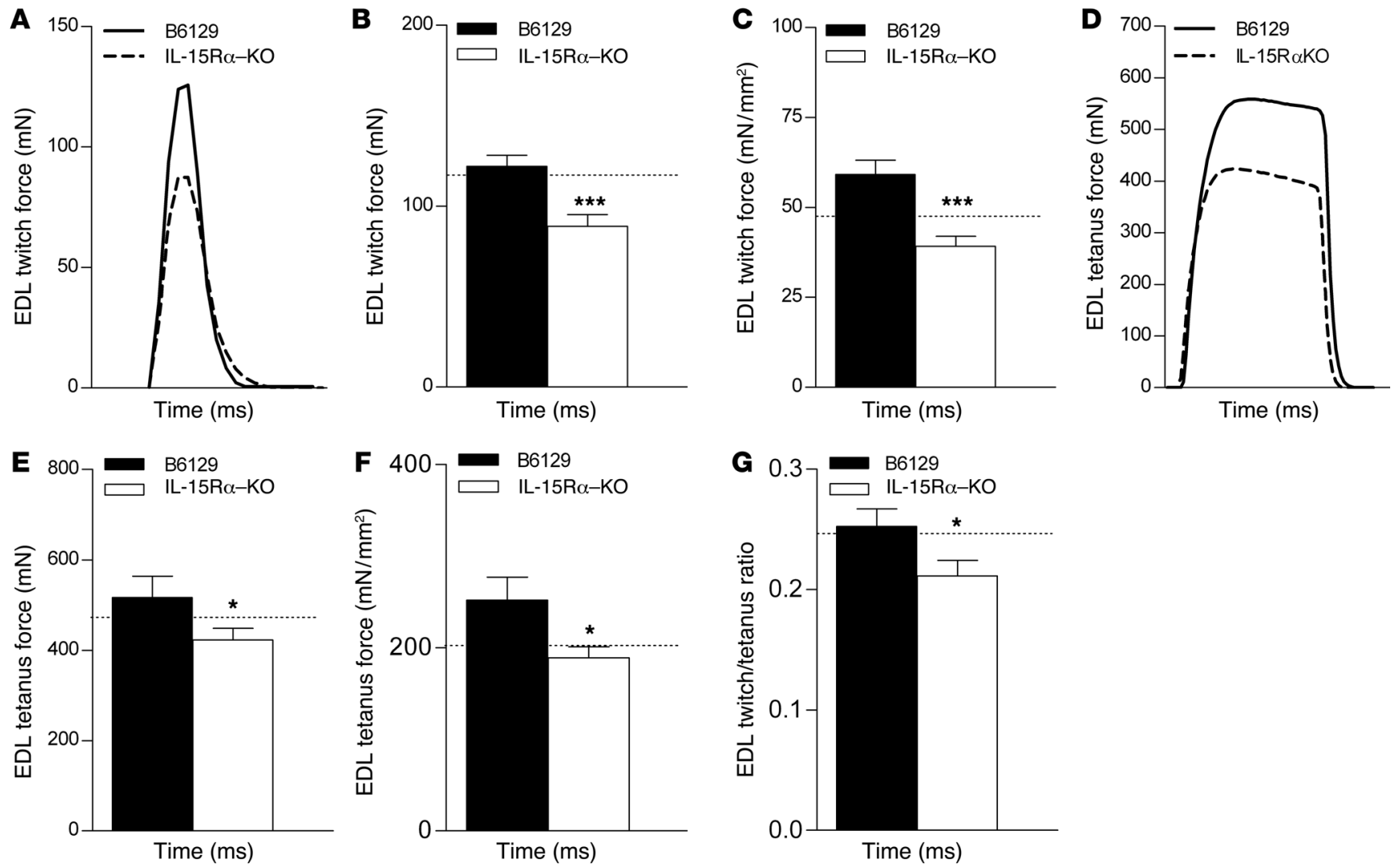

\section{Figure 2}

Altered isometric force production and resistance to fatigue in fast muscles from IL-15R $\alpha-K O$ mice. The fast EDL muscles from IL-15R $\alpha-K O$ mice $(n=21)$ and B6129 control mice $(n=16)$ were stimulated ex vivo to quantify isometric force production and fatigue properties. (A) Representative twitch contraction force traces. (B) Absolute twitch force was $27.1 \%$ less in EDL muscles from IL-15R $\alpha-K O$ mice compared with control. (C) When force was normalized to muscle CSA, twitch force was $33.9 \%$ less. (D) Representative tetanic contraction traces. (E) Absolute tetanic force was $18.2 \%$ less in EDL muscles from IL-15R $\alpha-K O$ mice compared with control. (F) When force was normalized to muscle CSA, tetanic force was $24.9 \%$ less. (G) The twitch/tetanus ratio was significantly lower in EDL muscles from IL-15R $\alpha-K O$ mice. Dotted lines represent values for wild-type C57BL/6 mice. Data are presented as mean \pm SD. ${ }^{*} P<0.05$, ${ }^{* *} P<0.0001$. 
Table 2

Anatomical and physiological properties of the soleus muscle

$\begin{array}{lcc}\text { Soleus } & \text { B6129 } & \text { IL-15R } \alpha-\mathbf{K O} \\ \text { Muscle weight }(\mathrm{mg}) & 8.6 \pm 1.1 & 9.1 \pm 1.4 \\ \text { Muscle weight/body weight }\left(\mathrm{mg} / \mathrm{g}^{-1}\right) & 0.30 \pm 0.03 & 0.40 \pm 0.03^{\mathrm{A}} \\ \text { CSA }\left(\mathrm{mm}^{2}\right) & 1.1 \pm 0.13 & 1.1 \pm 0.17 \\ \mathrm{~L}_{0}(\mathrm{~mm}) & 12.0 \pm 0.9 & 12.5 \pm 0.5 \\ \text { Total fiber number } & 841.9 \pm 74.0 & 926.3 \pm 133.0 \\ \text { Single-fiber area }\left(\mu \mathrm{m}^{2}\right) & 1096.3 \pm 389.7 & 1097.5 \pm 343.9 \\ \text { CNFs }(\%) & 3.2 \pm 2.2 & 4.4 \pm 2.0 \\ \text { Contraction time }(\mathrm{ms}) & 80.0 \pm 10.0 & 76.0 \pm 5.4 \\ \text { Rate of force development }\left(\mathrm{mN}^{\circ} \mathrm{s}^{-1}\right) & 326.1 \pm 185.0 & 306.8 \pm 110.9 \\ \text { 1/2 RT }(\mathrm{ms}) & 198.6 \pm 53.1 & 186.0 \pm 39.1 \\ \text { Rate of relaxation }\left(\mathrm{mN} \bullet \mathrm{s}^{-1}\right) & 143.0 \pm 104.1 & 130.6 \pm 55.7 \\ \text { Twitch/tetanus ratio } & 0.16 \pm 0.08 & 0.15 \pm 0.05\end{array}$

imal twitch contractions were significantly lower in EDL muscles from IL-15R $\alpha-\mathrm{KO}$ mice compared with B6129 control mice (Table 1). No differences in contractile parameters were observed in soleus muscles from IL-15R $\alpha-\mathrm{KO}$ mice (Supplemental Figure 2 and Table 2) or when comparing contractile parameters in muscles from IL-15-KO mice and BL/6NTac control mice or HSA-IL-15TG mice and HSA-IL-15Con mice (data not shown). These data provide additional physiological evidence for a remodeling of fast skeletal muscles in IL-15R $\alpha$-KO mice. Specifically, lower isometric forces coupled with a lower twitch/tetanus ratio and lower rates of force development and relaxation indicate that EDL muscles from IL-15R $\alpha-\mathrm{KO}$ mice have adopted a slower contractile phenotype. This phenotype is consistent with an oxidative shift, as highly oxidative fibers typically display similar twitch properties.

significantly lower in EDL muscles from IL-15R $\alpha-\mathrm{KO}$ mice compared with B6129 control mice, suggesting the presence of slow motor units in this normally fast muscle (Figure $2 \mathrm{G}$ ). In addition, the rate of force development and rate of relaxation during max-
Exercise performance and spontaneous cage activity in IL-15R $\alpha-K O$ mice. To determine the effects of the loss of IL-15R $\alpha$ on exercise performance in vivo, we quantified activity of IL-15R $\alpha-\mathrm{KO}$ mice and B6129 control mice using two different assays: cage wheel running and quantification
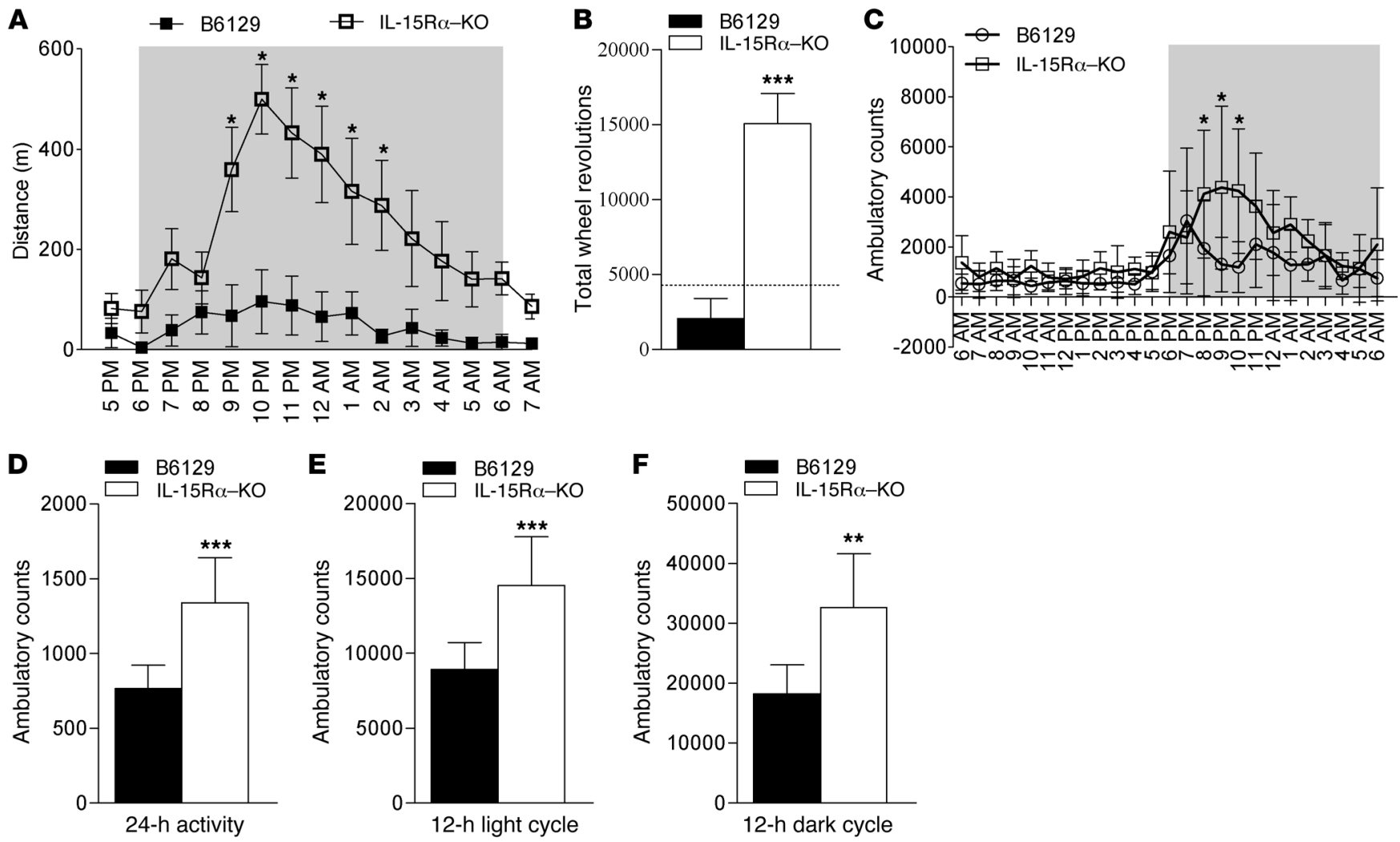

Figure 3

Increased exercise performance and ambulatory activity in IL-15R $\alpha-$ KO mice. (A) Running distance per hour in IL-15R $\alpha-K O$ mice $(n=12)$ and B6129 mice $(n=8)$. Gray indicates dark phase. (B) The total number of wheel revolutions during the 14-hour data collection period was 6-fold greater in IL-15Ro-KO mice compared with B6129 mice. The dashed line represents wheel running data in C57BL/6 wild-type mice. (C) Ambulatory activity in separate cohorts of IL-15R $\alpha-\mathrm{KO}$ mice $(n=8)$ and B6129 mice $(n=8)$. The number of ambulatory counts was significantly greater when expressed as (D) average counts in a 24-hour period, (E) total ambulatory counts during the 12-hour light cycle, and (F) total ambulatory counts during the 12-hour dark cycle. Knockout and background control mice were analyzed by $t$ test, and data are presented as mean \pm SD. ${ }^{\star} P<0.05,{ }^{* *} P<0.001,{ }^{* *} P<0.0001$. 

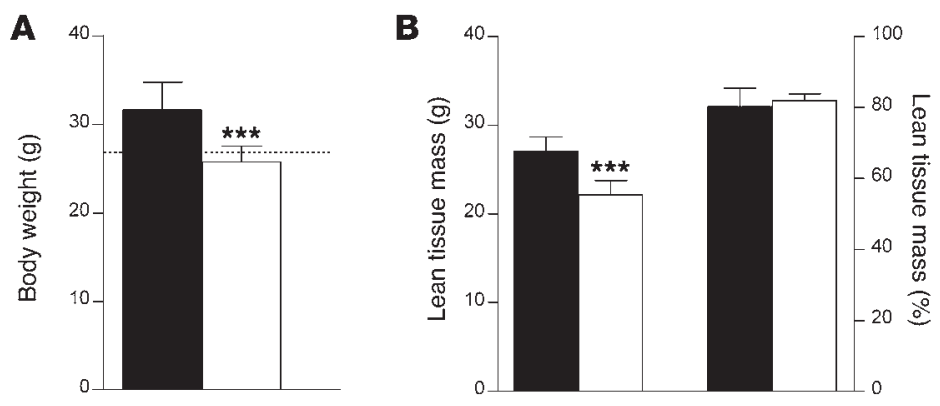

Skeletal muscle weights

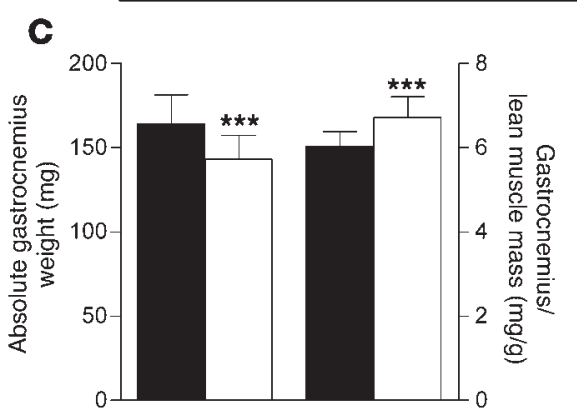

D

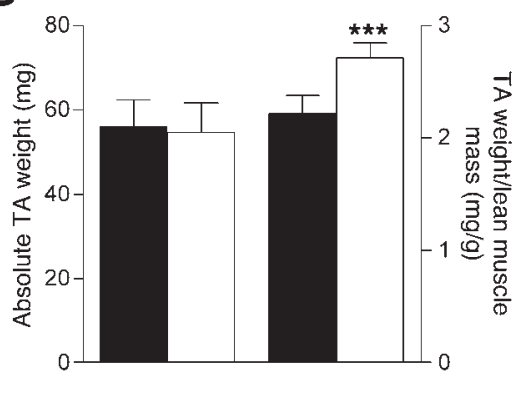

$\mathbf{E}$

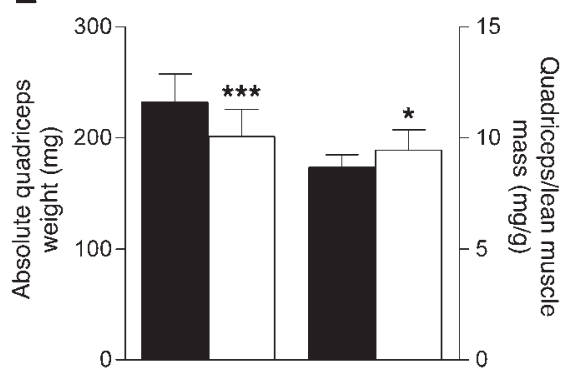

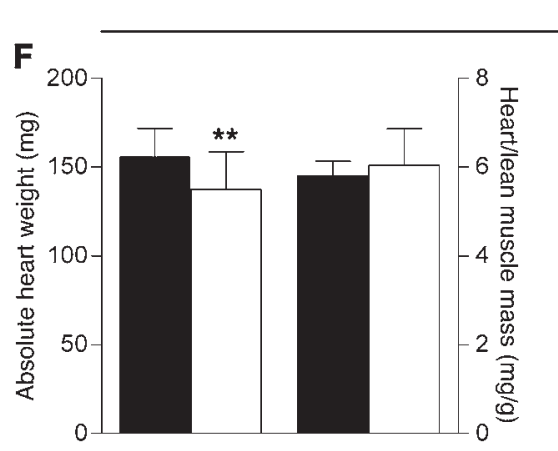
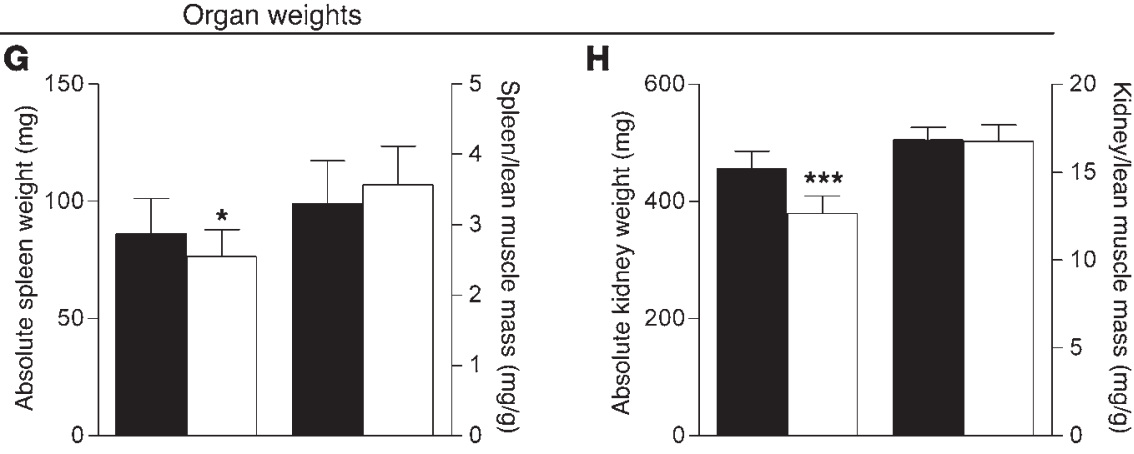

Figure 4

Body weight, skeletal muscle, and organ weights in IL-15R $\alpha-$ KO mice. (A) The body weight of IL-15R $\alpha-K O$ mice $(n=20)$ was $19 \%$ less than that of B6129 control mice $(n=16)$. (B) Lean muscle mass, assessed using NMR, was $18 \%$ less in IL-15R $\alpha-K O$ mice $(n=8)$ compared with B6129 control mice $(n=8)$. No differences were observed when lean muscle mass was expressed as a percentage of total body weight. The gastrocnemius, TA, and quadriceps muscles were dissected and weighed to compare absolute muscle weight and muscle/lean muscle mass ratios. The absolute weight of the gastrocnemius $(\mathbf{C})$ and the quadriceps $(\mathbf{E})$ muscles from IL-15R $\alpha-\mathrm{KO}$ mice $(n=40$ muscles) were significantly lower than those of $\mathrm{B} 6129$ control mice ( $n=32$ muscles). When normalized to lean muscle mass, the gastrocnemius, TA (D), and quadriceps muscle weight of IL-15R $\alpha-\mathrm{KO}$ mice was significantly greater than in B6129 control mice. The absolute weight of hearts (F), spleens (G), and kidneys $(\mathbf{H})$ from IL-15R $\alpha-$ KO mice ( $n=20$ organs) was significantly less than B6129 control mice ( $n=16$ organs). No differences were observed in the organ to lean body mass ratios in these tissues. These data demonstrate a preferential effect of loss of IL-15R $\alpha$ in skeletal muscle tissue, when compared with other tissue types. Data are presented as mean $\pm \mathrm{SD}$. ${ }^{*} P<0.05,{ }^{* \star} P<0.001,{ }^{* \star} P<0.0001$.

of photobeam breaks. Assays of spontaneous cage activity were used as surrogate measures of exercise capacity and were chosen to avoid stresses associated with forced exercise (i.e., mild electric shocks). As a measure of exercise performance, experimental mice were allowed free access to cage running wheels for a 14-hour period that included the 12-hour dark cycle. Running activity data were acquired via magnetic wheel counters that allowed data acquisition on the total number of wheel revolutions, which could be converted to total running distance. As shown in Figure 3A, IL-15R $\alpha-\mathrm{KO}$ mice were more active during the dark cycle compared with $\mathrm{B} 6129$ control mice. When the total number of wheel revolutions was quantified during the 14-hour data collection period, IL-15R $\alpha-\mathrm{KO}$ mice produced 15,090 wheel revolutions (equivalent to $5.4 \mathrm{~km}$ ), 6.3-fold more than the $\mathrm{B} 6129$ control mice (Figure 3B). IL-15R $\alpha-\mathrm{KO}$ mice also produced a greater number of wheel revolutions than wild-type C57BL/ 6 mice, as depicted by the dashed line in Figure 3B.

As another indirect measure of exercise capacity, we analyzed spontaneous cage activity for a 24-hour period using a Comprehensive Laboratory Animal Monitoring System (CLAMS; see Methods). Separate cohorts of B6129 control mice $(n=8)$ and IL-15R $\alpha-\mathrm{KO}$ mice $(n=8)$ were housed individually in cages designed to measure ambulatory activity by counting the number of photobeam breaks that occurred 
A

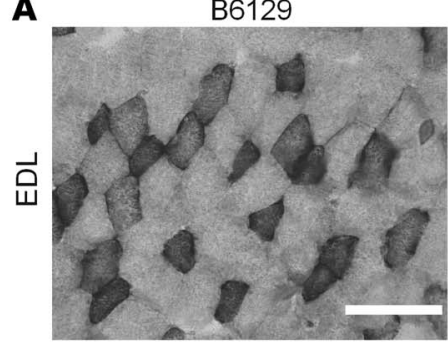

C

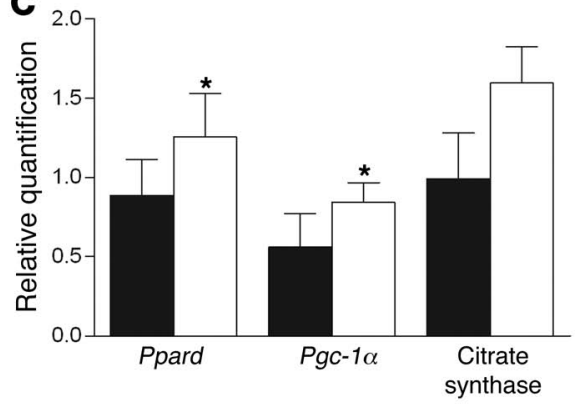

$\mathbf{F}$

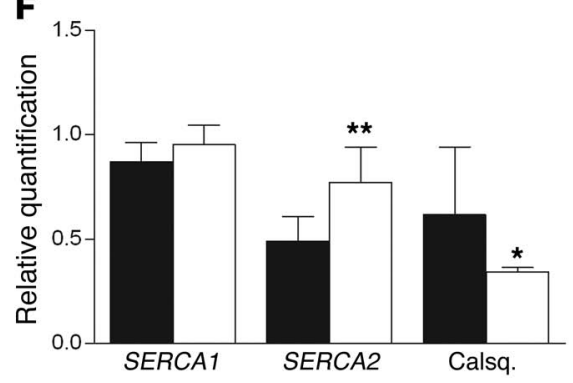

$\mathrm{IL}-15 \mathrm{R} \alpha-\mathrm{KO}$

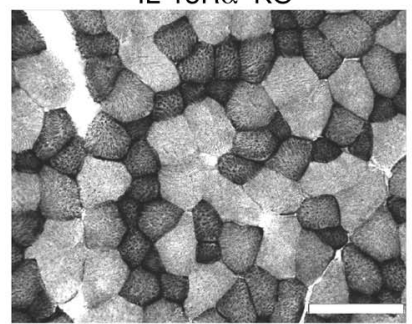

D

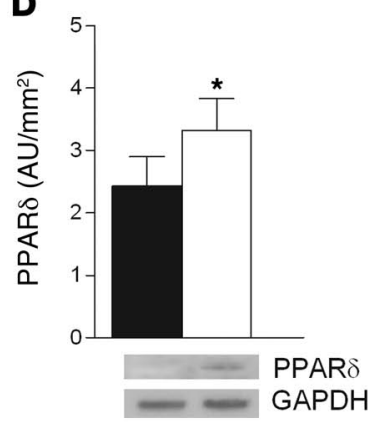

G

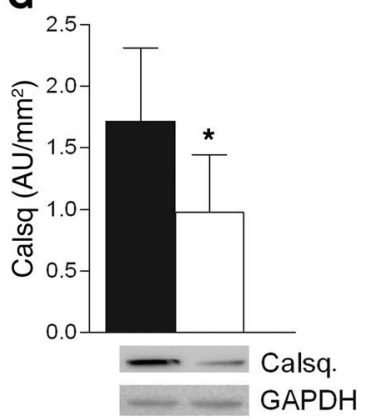

B

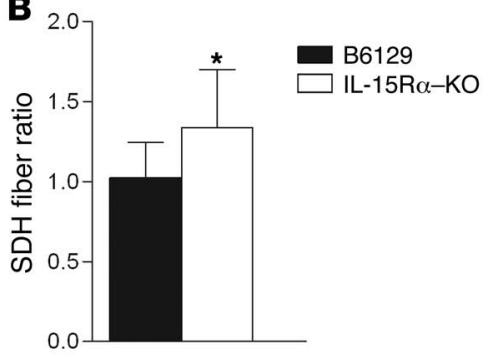

E

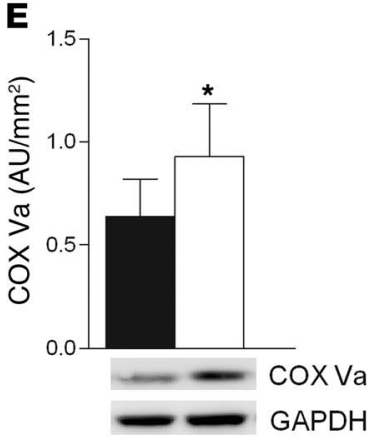

H

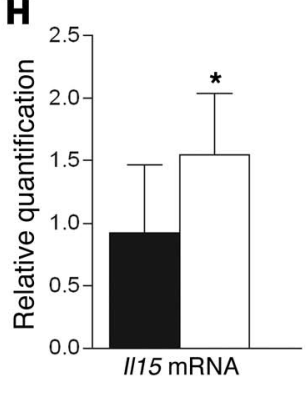

\section{Figure 5}

Molecular signature of muscles from IL-15R $\alpha-K O$ mice. Mitochondrial biogenesis and calcium homeostasis. Selected markers related to mitochondrial biogenesis and calcium homeostasis were examined at the gene and protein levels. (A) Fast EDL muscles from IL-15R $\alpha-K O$ mice $(n=8)$ and B6129 control mice $(n=8)$ were stained for SDH activity, a classical marker of mitochondria. (B) The SDH fiber ratio was significantly elevated in EDL muscles from IL-15R $\alpha-K O$ mice, indicating a greater number of fibers staining positive for SDH activity. (C) Gene expression was greater for Ppard, Pgc-1 $\alpha$, and citrate synthase in muscles from IL-15R $\alpha-K O$ mice, as determined by qPCR. (D) Greater protein abundance for PPAR $\delta$ in muscles from IL-15R $\alpha-K O$ mice. (E) Greater protein abundance for the COX subunit Va in muscles from IL-15R $\alpha-K O$ mice. (F) Gene expression was greater for the SERCAll isoform and lower for calsequestrin (Calsq.) in muscles from IL-15R $\alpha-\mathrm{KO}$ mice, as determined by qPCR. (G) Less protein level for calsequestrin in muscles from IL-15R $\alpha-K O$ mice. (H) Gene expression for $/ 115$ was greater in muscles from IL-15R $\alpha-$ KO mice, as determined by qPCR. Data are presented as mean \pm SD. ${ }^{*} P<0.05,{ }^{* \star} P<0.001,{ }^{* *} P<0.0001$. Scale bars: $100 \mu \mathrm{m}$.

every hour. All mice were housed in the cages for 3 days, with data collected on the third day of the experiment. Supporting the running wheel data, IL-15R $\alpha-\mathrm{KO}$ mice were more active than B6129 control mice (Figure 3C). During the 24-hour data collection period, IL-15R $\alpha-$ KO mice had 74\% higher ambulatory counts than B6129 control mice (Figure 3D). When data were separated based on the light and dark cycles, IL-15R $\alpha-\mathrm{KO}$ mice had $63 \%$ higher ambulatory counts during the light cycle (Figure 3E) and $80 \%$ higher ambulatory counts during the dark cycle (Figure 3F) compared with B6129 control mice. These data suggest that exercise capacity is greater in IL-15R $\alpha-\mathrm{KO}$ mice and is consistent with the increased resistance to fatigue observed in fast EDL muscles from these mice.

Body composition in IL-15R $\alpha-K O$ mice. At 10-11 weeks of age, male IL-15R $\alpha-\mathrm{KO}$ mice weighed $18.7 \%$ less than $\mathrm{B} 6129$ control mice (Figure 4A). Body composition, assessed using NMR, was used to assess lean muscle and adipose tissue mass. Lean muscle mass was $18.2 \%$ less in IL-15R $\alpha-\mathrm{KO}$ mice compared with B6129 mice (Figure 4B). However, when lean mass was expressed as a percentage of overall body weight, there were no significant differences between strains. There were no differences in adipose tissue mass between strains when values were expressed in absolute terms (IL-15R $\alpha-\mathrm{KO}: 3.8 \pm 0.2 \mathrm{~g}, n=8$; B6129: $5.1 \pm 0.8 \mathrm{~g}, n=8 ; P=0.0998$ ) or as a percentage of total body weight.

Based on the lean muscle mass measures presented above, individual muscles and organs from B6129 control mice and IL-15R $\alpha-$ $\mathrm{KO}$ mice were dissected and weighed. The absolute wet weight of gastrocnemius and quadriceps muscles from IL-15R $\alpha-\mathrm{KO}$ mice was significantly lower when compared with muscles from B6129 mice. However, when muscle weights were normalized to lean muscle mass, the muscle/lean muscle mass ratios for the gastroc- 

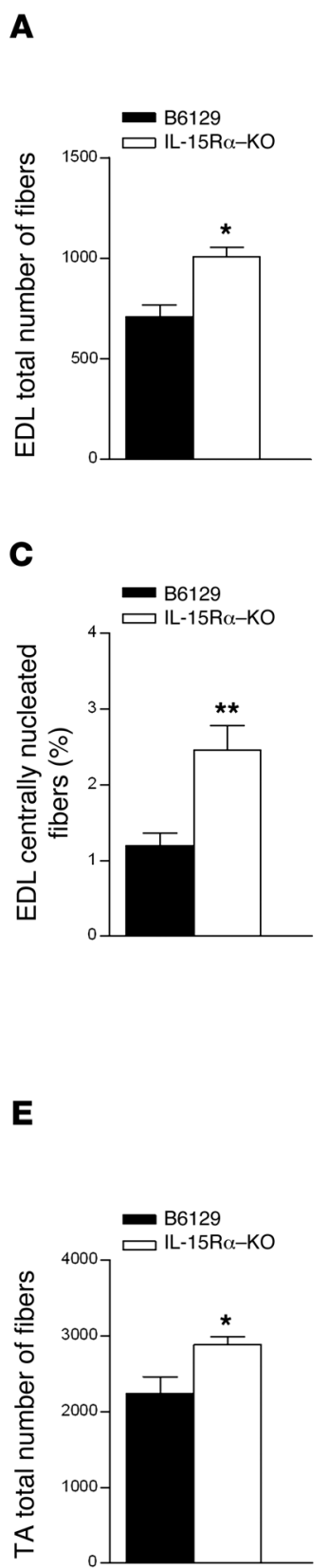

G

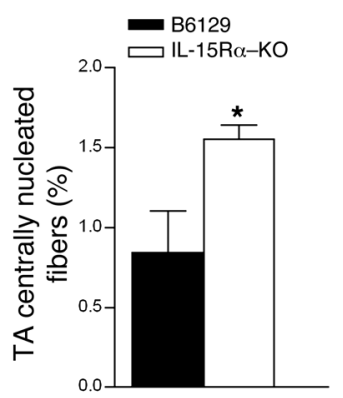

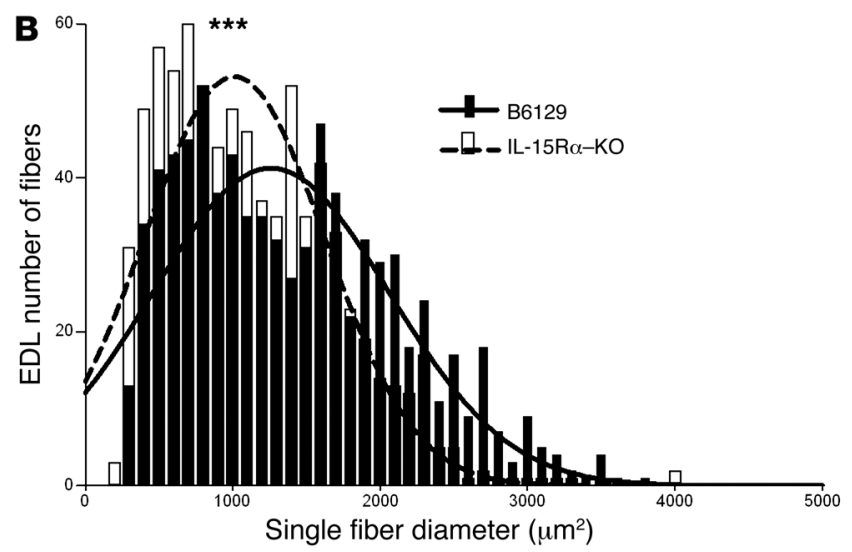

D
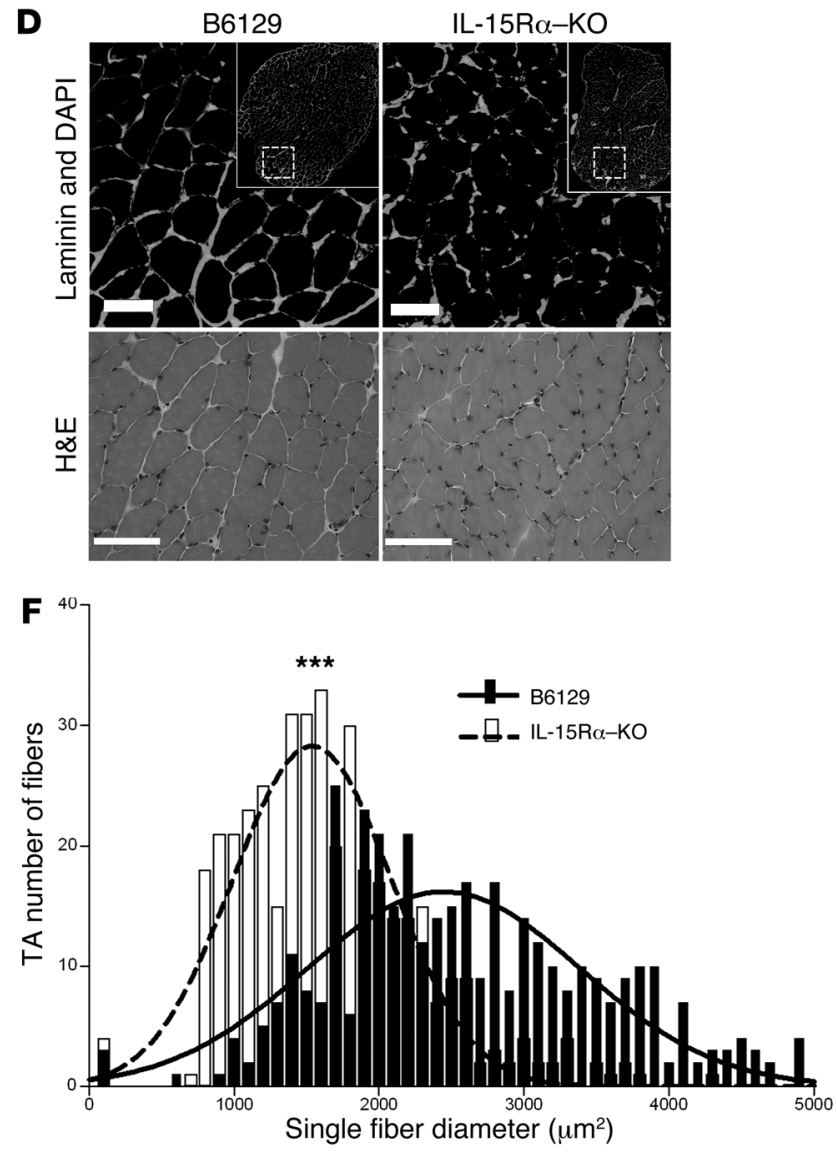

H

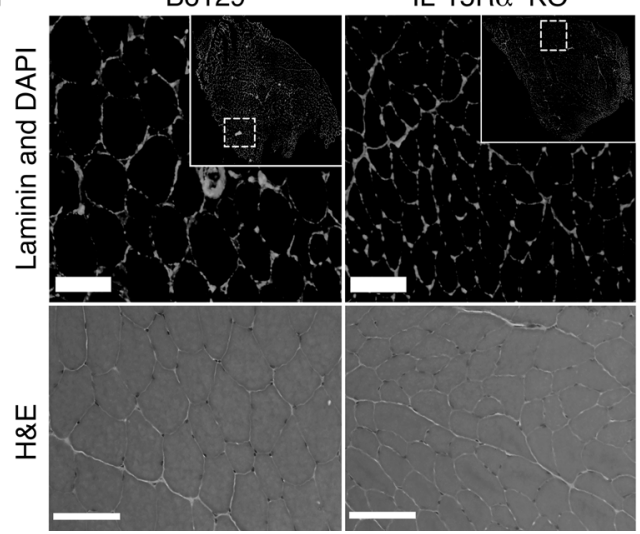

\section{Figure 6}

Muscle morphology in EDL and TA muscles from IL-15Ra-KO mice. The EDL and TA muscles were used for morphological examination. (A) The total number of muscle fibers in laminin-stained EDL muscle sections from IL-15Ra-KO mice was greater compared with B6129 control. (B) The single-fiber area histogram was shifted to the left, indicating a greater number of smaller-sized muscle fibers in the EDL muscles from IL-15Ra-KO mice. (C) The percentage of CNFs was significantly greater in EDL muscles from IL-15Ra-KO mice compared with B6129 control. (D) Representative laminin- and H\&E-stained EDL muscle sections demonstrate these morphological changes. (E) The total number of muscle fibers counted in laminin-stained TA muscle sections from IL-15Ra-KO mice was greater compared with B6129 control. (F) The single-fiber area histogram was shifted to the left, indicating a greater number of smaller-sized muscle fibers in the TA muscles from IL-15Ra-KO mice. (G) The percentage of CNFs was significantly greater in TA muscles from IL-15Ra-KO mice compared with B6129 control. (H) Representative laminin and $\mathrm{H} \& \mathrm{E}$-stained TA muscle sections demonstrate these morphological changes. Data are presented as mean \pm SD. ${ }^{*} P<0.05,{ }^{* *} P<0.001$, ${ }^{* \star *} P<0.0001$. Scale bars: $100 \mu \mathrm{m}$. 


\section{Table 3}

Associations of IL15RA SNP with athlete status

\begin{tabular}{|c|c|c|c|c|c|c|c|c|c|c|c|c|c|c|}
\hline \multirow{3}{*}{ Sport } & \multirow{3}{*}{ Endurance/sprint } & \multirow{3}{*}{ Sex } & \multirow{3}{*}{ Total } & \multirow{3}{*}{ Olympians } & \multicolumn{6}{|c|}{ Genotype } & \multicolumn{4}{|c|}{ Allele frequency } \\
\hline & & & & & \multicolumn{2}{|c|}{ AA } & \multicolumn{2}{|c|}{$A C$} & \multicolumn{2}{|c|}{ CC } & \multirow[t]{2}{*}{$P$} & \multirow[t]{2}{*}{ A allele $\%$} & \multirow[t]{2}{*}{ C allele \% } & \multirow[t]{2}{*}{$P$} \\
\hline & & & & & $\%$ & $n$ & $\%$ & $n$ & $\%$ & $n$ & & & & \\
\hline All cycling & Both & $M$ and $F$ & 73 & $23 \%$ & 29 & 21 & 59 & 43 & 12 & 9 & 0.052 & 58 & 42 & $0.027^{A}$ \\
\hline Road cycling & Endurance & $\mathrm{M}$ and $\mathrm{F}$ & 43 & $37 \%$ & 26 & 11 & 63 & 27 & 12 & 5 & $0.042^{\mathrm{A}}$ & 57 & 43 & 0.111 \\
\hline Swimming & Both & $\mathrm{M}$ and $\mathrm{F}$ & 39 & $41 \%$ & 26 & 10 & 67 & 26 & 8 & 3 & $0.010^{\mathrm{A}}$ & 59 & 41 & 0.059 \\
\hline Surf lifesaving & Endurance & $\mathrm{M}$ and $\mathrm{F}$ & 12 & $8 \%$ & 25 & 3 & 17 & 2 & 58 & 7 & $0.021^{\mathrm{A}}$ & 33 & 67 & 0.088 \\
\hline AIS triathlon & Endurance & $\mathrm{M}$ and $\mathrm{F}$ & 13 & $0 \%$ & 8 & 1 & 31 & 4 & 62 & 8 & 0.866 & 23 & 77 & $0.005^{A}$ \\
\hline Elite rowing & Endurance & $\mathrm{M}$ and $\mathrm{F}$ & 26 & $100 \%$ & 12 & 3 & 46 & 12 & 42 & 11 & 1 & 35 & 65 & $0.028^{A}$ \\
\hline
\end{tabular}

$\mathrm{M}$, male; F, female. "Olympians" refers to members of the AIS who qualified and competed at an Olympic games. ${ }^{A} P<0.05$.

nemius, tibialis anterior (TA), quadriceps (Figure 4, C-E), and EDL muscles (Table 1) from IL-15R $\alpha$-KO mice were significantly greater than ratios for B6129 mice. The absolute wet weight of heart, spleen, and kidney tissues was significantly lower in IL-15R $\alpha-\mathrm{KO}$ mice compared with B6129 mice. However, when these organ weights were normalized to lean muscle mass, the organ/lean muscle mass ratios were not significantly different from B6129 control mice (Figure 4, F-H). These data demonstrate a preferential effect of loss of IL-15R $\alpha$ on normalized skeletal muscle mass that is not seen in non-skeletal muscle tissue (i.e., heart, spleen, kidney).

Molecular signature of muscles from IL-15R $\alpha-K O$ mice: mitochondrial biogenesis, calcium homeostasis, and IL-15 expression. Based on our observations of altered fatigue resistance and muscle contractile parameters, we further examined muscles from IL-15R $\alpha$ and B6129 mice at the molecular level to determine a mechanism(s) for these changes. To determine muscle oxidative capacity, we stained EDL muscles for succinate dehydrogenase (SDH) activity, a classical measure of mitochondrial content/activity and an indirect measure of oxidative capacity (35). As shown in the representative images, there was a greater number of SDH-positive dark fibers in EDL muscles from IL-15R $\alpha-\mathrm{KO}$ compared with B6129 mice, indicating an increase in SDH activity (Figure 5A). To quantify these data, we calculated the dark/light fiber ratio, which was significantly elevated in these muscles (Figure 5B). The expression of mRNA for factors involved in promoting mitochondrial biogenesis, including the transcription factor Ppard, the PPAR $\delta$ coactivator Pgc-1 $\alpha$, and citrate synthase was greater in gastrocnemius muscles from IL-15R $\alpha-\mathrm{KO}$ relative to B6129 control (Figure 5C); however, levels of these genes were unchanged in spleen and kidney (data not shown). At the protein level, muscles from IL-15R $\alpha-\mathrm{KO}$ mice contained more PPAR $\delta$ as well as cytochrome $c$ oxidase (COX) subunit $\mathrm{Va}$, the subunit responsible for partially regulating the activity of the COX unit (ref. 36 and Figure 5, D and E). These data confirm the alteration in mitochondria, ascertained by SDH fiber quantification in EDL muscles from IL-15R $\alpha-\mathrm{KO}$ mice. In addition, gastrocnemius muscles from IL-15R $\alpha-\mathrm{KO}$ mice expressed higher levels of mRNA for the sarcoplasmic endoplasmic reticulum calcium ATPase-II (SERCA2) and lower mRNA expression and protein content of the calcium-binding protein calsequestrin (Figure 5, F and G). These changes in mitochondria- and calcium-related markers occurred without any changes in the myosin heavy chain isoform composition of these muscles, as assessed by quantitative PCR (qPCR) (data not shown). Collectively, these data provide a molecular signature of muscles from IL-15R $\alpha-\mathrm{KO}$ mice that explains, in part, the increased fatigue resistance in the fast EDL muscles along with the increased exercise capacity in these mice.
Il15 mRNA expression was greater in muscles from IL-15R $\alpha-\mathrm{KO}$ relative to $\mathrm{B} 6129$ mice, suggesting a compensatory upregulation of Il15 mRNA in the absence of IL-15R $\alpha$ (Figure 5H). Conversely, no changes in Il15ra mRNA were observed in muscles from IL-15KO or HSA-IL-15TG mice, nor was there a difference in IL-15R $\alpha$ expression when comparing fast and slow muscles from B6129 control mice (data not shown).

Fast versus slow muscle morphology in $I L-15 R \alpha-K O$ mice. Fast muscles (EDL, TA) and slow muscles (soleus) were sectioned and stained with a laminin antibody and DAPI to highlight myofiber membranes and myonuclei. Fluorescence images were used to quantify the following muscle morphological parameters: total fiber number, single-fiber CSA, total nuclei, the percentage of centrally nucleated fibers (CNFs), and the nuclei/single-fiber area ratio. Quantification of total fiber number from laminin/ DAPI-stained sections revealed a $28 \%$ greater number of total muscle fibers in EDL muscles and a $29 \%$ greater number of total muscle fibers in TA muscles from IL-15R $\alpha-\mathrm{KO}$ mice compared with B6129 controls (Figure 6, A and E). Quantification of single-fiber CSA revealed a leftward shift of the single-fiber area histogram in both EDL and TA muscles from IL-15R $\alpha-\mathrm{KO}$ mice, indicating a greater number of smaller-sized muscle fibers (Figure $6, \mathrm{~B}$ and $\mathrm{F}$ ). The total number of nuclei expressed relative to average fiber CSA was higher in muscles from IL-15R $\alpha-\mathrm{KO}$ compared with control mice (Supplemental Figure 3), a phenotype typically observed in slow skeletal muscles $(37,38)$. In addition, the percentage of centrally nucleated muscle fibers was also significantly increased in both EDL and TA muscles from IL-15R $\alpha-$ KO compared with control mice (Figure 6, C and G). Representative images of EDL and TA muscles stained with laminin/DAPI and H\&E demonstrate these morphological changes (Figure 6, D and H). In contrast, no differences were observed in total fiber number, single-fiber area, or CNF percentage in soleus muscles from these mice (Table 2). Together, these data demonstrate the altered muscle morphology specific to fast muscles from IL-15R $\alpha-\mathrm{KO}$ mice, suggesting that IL-15R $\alpha$ has a role in regulating the plasticity of fast EDL muscles.

A SNP in the buman IL15RA gene is associated with endurance in athletes. SNPs in the human IL15RA gene have been associated with skeletal muscle phenotypes $(16,17)$. One reported SNP in exon 3 results in an amino acid change at this position (i.e., non-synonymous SNP; rs2228059) (39). Therefore, we assessed the genotype and allelic frequency of this SNP in elite athletes participating in 11 different sports differing in dependence on endurance. Stratification of endurance and sprint athletes based on sport 
classification resulted in significant genotypes and allele frequencies (Table 3). Specifically, significant genotypes were observed in endurance athletes participating in road cycling, swimming, and surf lifesaving. Significant allele frequencies were observed, such that all cyclists had a greater percentage of the A allele, while triathletes and elite rowers had a greater percentage of the $\mathrm{C}$ allele (Table 3). Genotype and allele frequency analyses did not result in significant associations when the combined endurance versus sprint athletes were compared (Supplemental Table 1). These data demonstrate that SNP rs2228059 in the human IL15RA gene is associated with endurance athlete status in specific sports. These data support our exercise and skeletal muscle observations in the IL-15R $\alpha-\mathrm{KO}$ mouse and provide the basis for further hypothesisdirected testing of the effect of SNPs in the IL15RA and IL15 genes on endurance-based activities in human populations.

\section{Discussion}

Biological activity of IL-15 in vivo is likely regulated through interactions with IL-15R $\alpha$, which may represent an important mechanism for controlling overall IL-15/IL-15R $\alpha$ signaling and/or biological activity. This study provides physiological and molecular data demonstrating that loss of IL-15R $\alpha$ in vivo results in remodeling of fast muscles to a slower, more oxidative phenotype, akin to the roles proposed for PGC-1 $\alpha$ and ACTN3 $(40,41)$. These observations were specific to the loss of IL-15R $\alpha$, as knockout of IL-15 and transgenic overexpression of IL-15 did not result in altered exercise and muscle phenotypes. If interactions between IL-15 and IL-15R $\alpha$ were to occur strictly as a secreted cytokine binding to a cell surface receptor, then similar exercise and muscle phenotypes would have been observed in both IL-15R $\alpha-\mathrm{KO}$ mice and IL-15$\mathrm{KO}$ mice, since ligand-receptor binding would have been interrupted in both of these mouse strains. Because the phenotypes were distinct in these knockout mouse models with respect to spontaneous cage activity and fast muscle isometric contractile characteristics, we can conclude that the roles of IL-15R $\alpha$ and IL-15 in vivo are distinct with regard to muscle function. On this basis, we propose that IL-15R $\alpha$ has a role in determining the contractile and morphological phenotypes of fast skeletal muscles in vivo. This hypothesis is supported by the allelic associations between a SNP in the human IL15RA gene and endurance athlete status.

Adding to the documented complexity of IL-15-related activity, multiple isoforms and splice variants of IL-15R $\alpha$ exist as both membrane-bound and soluble forms that can either inhibit or potentiate IL-15 biological activity (29-33). The current study demonstrates that complete knockout of IL-15R $\alpha$ results in a mouse with an increased capacity for activity and initiates a remodeling of fast skeletal muscles to a more oxidative phenotype, phenotypes that were specific to knockout of IL-15R $\alpha$. It is also interesting to note that deletion of IL-15 and overexpression of IL-15 did not result in opposite muscle physiological responses, suggesting that interaction of IL-15R $\alpha$ with IL-15 represents a mechanism by which biological activity of IL-15 is controlled. Indeed, the observation that knockout or transgenic overexpression of IL-15 did not alter exercise or muscle phenotypes strengthens this possibility. Furthermore, previous reports have not been able to demonstrate consistently that increasing IL-15 levels in vivo exerts a significant therapeutic effect in skeletal muscle $(11-13,34)$. However, reductions in soluble IL-15R $\alpha$ in aged muscle were correlated with reductions in circulating IL-15 levels $(6,7)$. These data clearly demonstrate that the relationship between IL-15 and IL-15R $\alpha$ is more complex than a ligand-mem- brane-bound receptor interaction, highlighting a unique and, to our knowledge, previously undefined role for IL-15R $\alpha$ in muscle physiology and morphology.

Several physiologic parameters were measured to characterize exercise and muscle properties in these mouse strains, and three key observations support our hypothesis of a role for IL-15R $\alpha$ in fast muscle phenotypes: (a) fast muscles with an increased resistance to fatigue; (b) fast muscles with isometric contractile properties more similar to those of slow muscles; and (c) greater total running activity in IL-15R $\alpha-\mathrm{KO}$ mice. Resistance to repeated contraction-induced fatigue is a hallmark characteristic of slow skeletal muscles such as the soleus and is due to a combination of increased mitochondrial volume, oxidative enzyme capacity, capillarity, and smaller muscle fiber sizes. In contrast, the fast EDL muscle fatigues quickly due to a lower mitochondrial volume, increased glycolytic enzyme capacity, reduced capillarity, and larger muscle fiber sizes (42). EDL muscle from IL-15R $\alpha-\mathrm{KO}$ mice displayed an increase in fatigue resistance greater than control EDL muscles, although this was not a full transition to a slow phenotype. Specifically, the fatigue index curve of the EDL from IL-15R $\alpha-\mathrm{KO}$ mice was indistinguishable from the fatigue index curve of a soleus muscle from a control mouse during the first 30-40 seconds of the repeated stimulation protocol. Also, compared with an EDL muscle from a control mouse, the fatigue curve was shifted entirely to the right during the first 70 seconds of the repeated stimulation protocol, after which the fatigue curves of EDL muscles from B6129 control and IL-15R $\alpha-\mathrm{KO}$ mice were not different. Previous studies have reported an increase in fatigue resistance in EDL muscles following genetic manipulation of Actn3 (40) and $P g c-1 \alpha$ (41), although differing fatigue protocols preclude direct comparison with the current data in the IL-15R $\alpha-\mathrm{KO}$ mouse.

The isometric contractile properties of EDL muscles from IL-15R $\alpha-\mathrm{KO}$ mice were also consistent with the adoption of a slower contractile phenotype. Force production in response to twitch and tetanic muscle contractions resulted in lower forces in EDL muscles from IL-15R $\alpha-\mathrm{KO}$ mice compared with B6129 control mice, and were visibly lower than forces from wild-type C57BL/ 6 mice. This was true whether force was expressed in absolute terms or normalized to muscle CSA, indicating a functional alteration of the muscle independent of size. Interestingly, the twitch/tetanus ratio in EDL muscles from IL-15R $\alpha-\mathrm{KO}$ mice was $15 \%$ lower than in EDL muscles from control mice. The lower value for the twitch/tetanus ratio observed in this study is consistent with a previous report noting lower twitch/tetanus ratio values in muscles composed of slower motor units (43), and similar findings have been previously reported in the Actn3-KO mouse (40). In addition, the altered rates of force development and relaxation suggest alterations in the regulation of intracellular calcium levels following maximal contractions, as are noted to occur in slow skeletal muscles (44). Last, spontaneous cage activity was more than 6-fold greater in IL-15R $\alpha-\mathrm{KO}$ mice compared with B6129 control mice, and this amount of cage running activity was greater than that noted in other mouse models, including the HIF- $1 \alpha-\mathrm{KO}$ mouse (45) and mice treated with PPAR agonists (46). Collectively, the muscle contractile and spontaneous running experiments clearly demonstrate a more oxidative phenotype that is specific to the loss of IL-15R $\alpha$.

Quantification of several parameters confirmed altered morphology in fast skeletal muscles deficient in IL-15R $\alpha$, and the data support the hypothesis that loss of IL-15R $\alpha$ promotes a slower, more oxidative muscle phenotype. Slow muscles that are tonically active (e.g., soleus muscle) are composed of muscle fibers with smaller CSAs (42). The single-fiber area histograms for both the EDL and TA muscles 
from IL-15R $\alpha-\mathrm{KO}$ mice were shifted to the left, indicating smaller fiber sizes. Interestingly, the single-fiber area histogram of soleus muscles from IL-15R $\alpha-\mathrm{KO}$ mice was not different from control, demonstrating a specific effect of IL-15R $\alpha$ knockout on fast muscle morphology. In addition, the total fiber number and the percentage of CNFs were greater in fast muscles from IL-15R $\alpha-\mathrm{KO}$ mice and were not different from control in the slow soleus muscle. Previous studies detailing mouse models of increased endurance capacity and oxidative potential, including PGC- $1 \alpha$ transgenic (41), HIF- $1 \alpha-\mathrm{KO}$ (45), and Actn3-KO mice (40), did not report changes in muscle fiber number. The ratio of nuclei per average single-fiber area was also larger in EDL and TA muscles from IL-15R $\alpha-\mathrm{KO}$ mice, an observation previously noted in slower skeletal muscle $(37,38)$. These morphological data highlight a unique feature of fast muscles that are IL-15R $\alpha$ deficient, which likely contributes to the slower contractile characteristics we observed in these normally fast muscles.

The molecular signature of muscles from IL-15R $\alpha-\mathrm{KO}$ mice provides a plausible mechanism for the altered exercise and muscle physiological properties we observed. Indeed, an analogy can be drawn to the extraocular muscles, which can contract rapidly for long periods of time and have a distinct molecular makeup compared with skeletal muscles (47-49). The increased resistance to fatigue of the fast EDL muscle in response to repeated stimulation suggested an alteration in mitochondrial content and/or function. The observation that SDH activity was greater in EDL muscles from IL-15R $\alpha-\mathrm{KO}$ mice supports the physiological demonstration of a greater resistance to fatigue in these fast muscles. In addition, knockout of IL-15R $\alpha$ results in an upregulation of PPAR $\delta$ and PGC-1 $\alpha$, along with changes in mitochondrial enzymatic activity and oxidative potential. The transcription factor PPAR $\delta$ and the coactivator PGC-1 $\alpha$ are important regulators of oxidative and mitochondrial genes. For example, slow muscles have greater amounts of PGC- $1 \alpha(41,50)$, and overexpression of PGC- $1 \alpha$ drives mitochondrial biogenesis and promotes an increase in oxidative potential, while PGC- $1 \alpha$-knockout mice have a reduced endurance capacity along with increased muscle fiber damage and inflammation following exercise $(41,51)$. The observations of altered rates of force development and relaxation during maximal twitch contractions suggested an alteration in calcium-related markers in the muscles from IL-15R $\alpha-\mathrm{KO}$ mice. Calcium kinetics as well as calcium-handling proteins differ between fast and slow muscles. The muscles from IL-15R $\alpha-\mathrm{KO}$ mice had a greater relative expression of the SERCAII isoform and lower mRNA and protein levels of calsequestrin, both characteristic of slow muscles (52). The observation of reduced calsequestrin in the muscles of IL-15R $\alpha-\mathrm{KO}$ mice is interesting inasmuch as calsequestrin concentrations are reported to be higher in fast muscles (52) and fast muscles from calsequestrin-1-null mice display contractile characteristics similar to those of slow muscles, including longer contraction times and half-relaxation times ( $\left.1 \frac{1}{2} \mathrm{RTs}\right)(53)$. These data demonstrate an altered molecular state of skeletal muscle deficient in IL-15R $\alpha$ that contributes to the changes noted in muscle function and cage activity.

IL-15R $\alpha-$ KO mice weighed almost $20 \%$ less than B6129 control mice, and this was reflected in the lower absolute weights of individual skeletal muscles. However, when muscle weights were normalized to lean muscle mass, the muscle/lean muscle mass ratios were greater in IL-15R $\alpha-\mathrm{KO}$ mice. This is interesting, given that muscle/lean muscle mass ratios of non-skeletal muscle organs from IL-15R $\alpha-\mathrm{KO}$ mice, such as the heart, spleen, and kidneys, were not significantly different from those of B6129 controls. These data demonstrate a preferential effect of loss of IL-15R $\alpha$ on normalized skeletal muscle weight, which may reflect alterations in overall body metabolism, as previously suggested (14). He et al. (14) measured horizontal and vertical beam breaks in a metabolic chamber and reported a significant increase in activity levels of female IL-15R $\alpha-\mathrm{KO}$ compared with control mice. Similarly, we observed that male IL-15R $\alpha-K O$ mice produced 6.3-fold more wheel revolutions compared with B1629 control mice in cage wheel running experiments and had a larger number of ambulatory photobeam breaks in the light and dark cycles. Although the cage running wheel system and the ambulatory photobeam break system used in the current study are measures of spontaneous activity, the dramatic increases observed in both studies reflect a consistent behavior of increased activity that suggests an increase in the capacity to perform exercise. He et al. (14) also report an increased $\mathrm{VO}_{2}$ and $\mathrm{VCO}_{2}$ in these mice, which, along with a leaner body composition, would suggest an altered metabolic phenotype, supporting the data in the current study. The upregulation of Il15 mRNA in skeletal muscles from IL-15R $\alpha-\mathrm{KO}$ mice reported in the current study could potentially contribute to the altered body composition observed in these mice (14), as HSA-IL-15TG mice had lower adiposity and were resistant to high-fat diet-induced obesity (34).

The contribution of central versus peripheral influences to the observed phenotype in the IL-15R $\alpha-\mathrm{KO}$ mouse has not been clarified. Both IL-15R $\alpha$ and IL-15 are expressed in the central nervous system, and circadian sleep patterns are altered with manipulation of these molecules, demonstrating an effect in these tissues (54-56). Recent studies have also suggested a role for IL-15R $\alpha$ in altering circadian rhythms of activity and thermoregulation (14), as well as in normal anxiety behavior (15). Although our data in the IL-15R $\alpha-\mathrm{KO}$ mouse do not provide an explanation for the influence of central versus peripheral mechanisms on the observed exercise and muscle contractile phenotypes, the ex vivo muscle physiological data demonstrate that the end result is altered fast muscle morphology and contractile characteristics. Since levels of PGC- $1 \alpha$ and citrate synthase were unchanged in spleen and kidney, in contrast to the situation in skeletal muscle, it would suggest that the mechanism of the increased endurance and altered metabolic characteristics is a muscle-specific adaptation to the lack of IL-15R $\alpha$. Experiments are being planned to delineate the central and peripheral mechanisms underlying the observed phenotype in these mice.

SNPs can modulate gene function and/or expression, and SNP association studies can provide preliminary data for further hypothesis-directed experiments. SNPs in the human IL15 and IL15RA genes have been associated with responses of skeletal muscle to resistance training (17), baseline measures of skeletal muscle and bone (16), and markers of the metabolic syndrome (16), suggesting a role for these genes in skeletal muscle. Numerous reported SNPs in the IL15RA gene occur at intron-exon borders, raising the possibility that these SNPs could affect expression levels, gene splicing, and/or processing $(16,17)$. In the current study, the genotype and allele frequency of a SNP in exon 3 of the IL15RA gene were associated with elite human endurance athletes stratified by sport. However, this was an exploratory analysis, and additional SNPs in the IL15 and IL15RA genes and additional cohorts of athletes should be screened to further define the association between genotype and certain types of athletic performance; these analyses are currently being pursued. These data are compelling, given the increased activity and metabolic characteristics of IL-15R $\alpha-\mathrm{KO}$ mice observed in the current study. 
In conclusion, our results support the hypothesis that IL-15R $\alpha$ has a role in defining the phenotype of fast skeletal muscles in vivo. Physiological evaluation of IL-15R $\alpha-\mathrm{KO}$ mice demonstrated increased exercise capacity and altered muscle contractile properties consistent with a transition of fast muscles toward a slower contractile phenotype. These altered physiological parameters may be explained by alterations in markers involved in mitochondrial biogenesis and calcium kinetics. Positive genetic associations (genotype, allele frequency) were found between a SNP in the IL15RA gene and endurance in athletes stratified by sport, suggesting a conserved role of IL-15R $\alpha$ and endurance. Although the current study demonstrates that loss of IL-15R $\alpha$ promotes this phenotype, future studies are needed to determine the roles of specific IL-15R $\alpha$ isoforms in muscle, as well as the associations of additional IL15RA polymorphisms in muscle phenotypes in humans. Our study highlights a heretofore unrecognized role for IL-15R $\alpha$ in muscle and the unique muscle and exercise phenotypes caused by IL-15R $\alpha$ deletion. We suggest these observations will have therapeutic implications for skeletal myopathies and systemic diseases such as diabetes and obesity and for the aged population, in which reduced endurance impacts mortality and activities of daily living (57); as well as societal implications in terms of altering athletic performance.

\section{Methods}

\section{Mice}

The following strains of male mice were purchased from The Jackson Laboratory at 8 weeks of age: IL-15R $\alpha-\mathrm{KO}$ mice (stock no. 003723; $n=20$ ); B6129SF2/J background control $(101045 ; n=16)$. The following strains of male mice were purchased from Taconic at 8 weeks of age: IL-15-KO $(004269 ; n=8)$; BL/6NTac background control (B6-M; $n=8)$. The generation and description of HSA-IL-15TG $(n=7)$ and HSA-IL-15Con $(n=7)$ mice have been previously published (34). C57BL/ 6 wild-type mice (The Jackson Laboratory, 000664; $n=8$ ) were used as an additional control for comparison purposes, but were not included in any statistical analyses. All mice were used for experiments between 10 and 12 weeks of age (i.e., as adults) (58). Mice were housed in the barrier controlled facility at the University of Pennsylvania at $22^{\circ} \mathrm{C}$ under a 12 -hour light/12-hour dark cycle and received food and water ab libitum. All animal experiments and protocols were approved by the Institutional Animal Care and Use Committee of the University of Pennsylvania.

\section{Cage wheel running}

Spontaneous activity was monitored using a cage running wheel system (Columbus Instruments). Computer software specific to the equipment was used to quantify the total number of wheel revolutions every hour during the 12-hour dark cycle, and for 1 hour before and 1 hour after the dark cycle. Data were expressed as both total wheel revolutions during the 14-hour data collection period and distance covered per hour.

\section{Spontaneous cage activity}

Locomotor activity was quantified through photobeam breaks in a Comprehensive Laboratory Animal Monitoring System (CLAMS; Columbus Instruments). Mice were housed singly in cages for 3 days and exposed to 12 -hour light/12-hour dark cycle and ambient temperature of $22^{\circ} \mathrm{C}$. Mice were allowed free access to food and water. Photobeam breaks were quantified for a 24-hour period on the third day of the experiment, as previously described (59).

\section{Body composition}

Body composition was determined using NMR quantification (Echo Medical Systems), as described previously (60).

\section{Ex vivo muscle physiological analysis}

Muscle contractile properties were examined in the EDL and soleus muscles. Parameters analyzed from isometric contractions included peak isometric twitch force (Pt), time to peak twitch tension (TPT), 1/2 RT, and peak isometric tetanic force (Po), as previously described (61). Data acquisition software (LabChart Pro v6, ADInstruments) was used to quantify the rate of force development of maximal twitch contraction (peak force $\cdot \mathrm{TPT}^{-1} ; \mathrm{mN} \cdot \mathrm{s}^{-1}$ ), and the rate of relaxation of maximal twitch contraction (peak force $1 / 2 \mathrm{RT}^{-1}$; $\mathrm{mN} \cdot \mathrm{s}^{-1}$ ). Isometric contractions were stimulated in muscles ex vivo using a Grass Technologies S48 stimulator at a stimulation frequency of $120 \mathrm{~Hz}$ for EDL muscles and $80 \mathrm{~Hz}$ for soleus muscles, a stimulation current of $28 \mathrm{~V}$, and duration of $500 \mathrm{~ms}$. Muscle fatigue was analyzed using a repeated stimulation protocol lasting 6 minutes and consisting of repeated $40-\mathrm{Hz}$ tetanic trains that occurred once every second and lasted $330 \mathrm{~ms}$ (62). Muscle length was adjusted to obtain the maximal twitch response (i.e., optimal length $\left.\left[\mathrm{L}_{\mathrm{o}}\right]\right)$. Muscles were stimulated in oxygenated Ringer's solution composed of $100 \mathrm{mM} \mathrm{NaCl}, 4.7 \mathrm{mM} \mathrm{KCl}, 3.4 \mathrm{mM} \mathrm{CaCl}_{2}, 1.2 \mathrm{mM} \mathrm{KH}_{2} \mathrm{PO}_{4}$, $1.2 \mathrm{mM} \mathrm{MgSO}_{4}, 25 \mathrm{mM}$ HEPES, and $5.5 \mathrm{mM}$ D-glucose. Three twitch contractions and 3 tetanic contractions were performed, each separated by 2 minutes. Following isometric contractions, the muscles remained in oxygenated Ringer's for 5 minutes prior to the repeated-stimulation fatigue protocol. The fatigue index was calculated as the difference in force from the first contraction and every tenth subsequent contraction, and plotted as a fatigue curve. Muscles were flash frozen in isopentane cooled to the temperature of liquid nitrogen and stored at $-80^{\circ} \mathrm{C}$. Muscle CSA was calculated by dividing the muscle mass by the product of the muscle density coefficient $\left(1.06 \mathrm{~g} \cdot \mathrm{cm}^{3}\right)$, muscle $\mathrm{L}_{\mathrm{o}}$, and the fiber length coefficient (EDL: 0.45 , soleus: 0.69$)$. This whole muscle CSA value was used to calculate specific force (i.e., absolute force $\mathrm{mN} \cdot$ muscle $\left.\mathrm{CSA}^{-1}\right)(63,64)$.

\section{Muscle bistology and morphology}

Frozen sections (10 $\mu \mathrm{m}$ thickness) were cut at the mid-abdomen of the muscle and fixed in ice-cold methanol for 5 minutes. Sections were processed for histological examination by $\mathrm{H} \& \mathrm{E}$ and $\mathrm{SDH}$ staining, as previously described (65). For morphological analyses, sections were stained with an anti-laminin monoclonal antibody (Sigma-Aldrich), incubated with Alexa Fluor 488-goat anti-mouse secondary antibody, mounted with DAPI (Vector), and visualized using epifluorescence illumination on an Olympus BX51 microscope. Digital images were acquired using an Olympus Magnafire digital camera. Morphologic analyses were completed in $\operatorname{EDL}(n=16)$, TA $(n=8)$, and soleus $(n=15)$ muscles from B6129 and IL-15R $\alpha$-KO mice. Laminin/DAPI- (EDL, TA) or H\&E-stained (soleus) sections were used for morphological measurement. The total number of fibers (EDL: 13,729; TA: 20,466; soleus: 13,303 ) and percentage of CNFs were manually calculated for both groups from stained sections acquired at the mid-abdomen area of the muscles. Muscle CSA and single-fiber area in both groups were measured using the NIH ImageJ area measurement program (http://rsb.info. nih.gov/ij/). Single-fiber areas were measured in all $\operatorname{EDL}(n=13,729)$ fibers and in 100 randomly selected fibers per muscle for TA $(n=800)$ and soleus $(n=1,500)$ and plotted as histograms.

\section{TaqMan qPCR}

Total RNA was isolated from gastrocnemius muscles, spleen, and kidney of IL-15R $\alpha$-KO mice and B6129 control mice as previously described (4). RNA quantity and integrity were assessed using a Nano-Drop 2000 Spectrophotometer (Thermo Scientific); the 260/280 ratio for all samples used 
was between 1.9 and 2.1. Two micrograms of total RNA was reverse transcribed to make cDNA using a high-capacity cDNA reverse transcription kit according to the manufacturer's instructions (Applied Biosystems). The wells of a 96-well optical reaction plate were loaded with a $20-\mu$ l volume consisting of TaqMan 10× PCR Master Mix, cDNA diluted in sterile $\mathrm{H}_{2} \mathrm{O}$, and either a primer mix for the gene of interest or the housekeeping gene 18s. The relative quantification of each gene was calculated using the $\Delta \Delta \mathrm{CT}$ method, with one control B6129 cDNA sample used as the calibrator.

\section{Western blot analyses}

Gastrocnemius muscles from IL-15R $\alpha-\mathrm{KO}$ and B6129 mice were homogenized using a mechanical homogenizer (Polytron) in lysis buffer $(50 \mathrm{mM}$ Tris- $\mathrm{HCl}$ pH 8.0, $150 \mathrm{mM} \mathrm{NaCl}, 1 \%$ IGEPAL 630, 2 mM EDTA, protease inhibitor). Soluble protein concentrations were determined using the DC assay, according to the manufacturer's instructions (Bio-Rad). Fifty micrograms of protein was loaded into $4 \%-12 \%$ NuPAGE BisTris Precast Gels (Invitrogen), separated by SDS-PAGE for 1.5 hours at room temperature, and transferred to PVDF membranes. Verification of equivalent protein loading and transfer was visualized by Ponceau $\mathrm{S}$ red stain (Sigma-Aldrich). The membranes were blocked in $5 \%$ nonfat milk (NFM) protein in Tris-buffered saline containing $0.05 \%$ Tween (TBS-T). Membranes were probed with the following primary antibodies diluted in TBS-T with 5\% NFM overnight at $4{ }^{\circ} \mathrm{C}$ : calsequestrin rabbit polyclonal antibody $(1: 2,000$ dilution, ab3516, Abcam), PPAR $\delta$ rabbit polyclonal antibody $\left(2 \mu \mathrm{g} \cdot \mathrm{ml}^{-1}\right.$ dilution, ab23673, Abcam), COX polypeptide Va mouse monoclonal antibody (1:1,000 dilution, MS409, MitoSciences), phosphorylated Smad2 (1:1,000 dilution, 3101, Cell Signaling Technology), Smad2/3 (1:1,000 dilution, 3102, Cell Signaling Technology), GAPDH rabbit polyclonal antibody (1:1,000 dilution, ab9485, Abcam). Secondary antibodies were conjugated with horseradish peroxidase, and signals were developed using a chemiluminescent substrate (Super Signal West Pico, Thermo Scientific). Signals were visualized and quantified using a Fujifilm LAS3000 luminescent image analyzer and accompanying software, and expressed as $\mathrm{OD} \times$ band area $\left(\mathrm{mm}^{2}\right)$ normalized to GAPDH signals from matched samples.

\section{Statistics}

All data were quantified and analyzed using the GraphPad Prism 5.0 statistical software package. Student's $t$ test was used to compare genetically modified mice with their respective background control mice. Data are presented as mean $\pm \mathrm{SD}$, and the null hypothesis was rejected when $P$ was less than 0.05 .

\section{IL15RA genotyping methodology}

Subjects. We genotyped 258 unrelated control individuals of European descent from three different sources (blood donors, healthy children participating in an unrelated study, and healthy adults participating in a talent identification program with the AIS). A total of 308 athletes of European descent were genotyped from 11 different sports. Elite athletes $(n=209)$ were independently classified at the AIS, prior to genotyping and division into sprint or endurance athletes. Specialist sprint/power athletes consisted of 37 track athletes competing in events of $\leq 800 \mathrm{~m}, 7$ swimmers competing in events $\leq 200 \mathrm{~m}, 2$ judo athletes, 7 short-distance track cyclists, and 3 speed skaters. Specialist endurance athletes included 43 long-distance cyclists, 4 swimmers competing over distances of $\geq 400 \mathrm{~m}, 20$ track athletes competing in events of $\geq 5,000 \mathrm{~m}, 3$ surf lifesavers, 13 tri-athletes, 4 multi-sport athletes, and 5 cross-country skiers. Athletes were also analyzed in subgroups of their specialized sport. This study was approved by the institutional review boards of the Children's Hospital at Westmead, the University of Sydney, and the AIS. Written informed consent was received from study participants.

Genotyping methodology. The rs2228059 SNP in IL-15R $\alpha$ was genotyped using PCR amplification, then digestion with restriction enzyme BsrI. The primer sequences were as follows: forward, $5^{\prime}$-AGCTTCATCTCCCAGCTCAA-3'; reverse, 5'-ACAGAGAAAGCCACGGAGAA-3'. Thermal cycling conditions for the PCR reaction were: $95^{\circ} \mathrm{C}$ for 5 minutes, $95^{\circ} \mathrm{C}$ for 30 seconds, $60^{\circ} \mathrm{C}$ for 30 seconds, and $72^{\circ} \mathrm{C}$ for 30 seconds, for 40 cycles, with a final extension of $72^{\circ} \mathrm{C}$ for 7 minutes. Overnight digestion with $B s r I$ was completed at $65^{\circ} \mathrm{C}$. The PCR fragment for the $\mathrm{C}$ allele has one BsrI site, which generated two fragments after digestion: $61 \mathrm{bp}$ and $346 \mathrm{bp}$. The A allele has an additional BsrI site, which generated 3 fragments: $61 \mathrm{bp}$, $140 \mathrm{bp}$, and $145 \mathrm{bp}$. Digested PCR fragments were separated by 10\% PAGE and stained with ethidium bromide. Genotype frequencies in control and athlete cohorts were analyzed using Hardy-Weinberg equilibrium, and no departure from expected values was found.

Statistical significance tests. To analyze the genetic association of IL15RA $\mathrm{A} / \mathrm{C}$ alleles (rs2228059) and genotype frequencies in athletes, we used a log-linear modeling approach previously applied in genetic association studies (66). It was first described by Huttley and Wilson (67) and was implemented using the statistical programming language $\mathrm{R}$ (version 2.10.1). After loading of the hwde package, $\chi^{2}$ values were estimated using genotype numbers for comparisons between athletes and controls.

\section{Acknowledgments}

This research was supported by the NIH under Ruth L. Kirschstein National Research Service Award 5T32AR053461 from the National Institute of Arthritis and Musculoskeletal and Skin Diseases (to E.E. Pistilli), EY013862 and AR48871 to T.S. Khurana, and R01AG024136 to L.S. Quinn, with resources from the VA Puget Sound Health Care System. The authors acknowledge Ravindra Dhir for collection and analysis of body composition and ambulatory activity data.

Received for publication March 29, 2011, and accepted in revised form May 23, 2011.

Address correspondence to: Tejvir S. Khurana, Department of Physiology, University of Pennsylvania School of Medicine, 3700 Hamilton Walk, A601 Richards Building, Philadelphia, Pennsylvania 19104, USA. Phone: 215.573.2640; Fax: 215.573.5851; E-mail: tsk@mail.med.upenn.edu.

Emidio E. Pistilli's present address is: Division of Exercise Physiology, Department of Human Performance and Applied Exercise Science, West Virginia University, Morgantown, West Virgina, USA.

Sasha Bogdanovich's present address is: Department of Ophthalmology and Visual Sciences, University of Kentucky College of Medicine, Lexington, Kentucky USA.
1. Grabstein $\mathrm{KH}$, et al. Cloning of a $\mathrm{T}$ cell growth factor that interacts with the beta chain of the interleukin-2 receptor. Science. 1994;264(5161):965-968.

2. Giri JG, et al. Identification and cloning of a novel IL-15 binding protein that is structurally related to the alpha chain of the IL-2 receptor. EMBO J. 1995;14(15):3654-3663.
3. Giri JG, et al. Utilization of the beta and gamma chains of the IL-2 receptor by the novel cytokine IL-15. EMBO J. 1994;13(12):2822-2830.

4. Pistilli EE, Siu PM, Alway SE. Interleukin-15 responses to aging and unloading-induced skeletal muscle atrophy. Am J Physiol Cell Physiol. 2007;292(4):C1298-C1304.
5. Nielsen AR, et al. Expression of interleukin-15 in human skeletal muscle effect of exercise and muscle fibre type composition. J Physiol. 2007; 584(pt 1):305-312.

6. Marzetti E, et al. Changes in IL-15 expression and death-receptor apoptotic signaling in rat gastrocnemius muscle with aging and life-long calorie 
restriction. Mech Ageing Dev. 2009;130(4):272-280.

7. Quinn LS, Anderson BG, Strait-Bodey L, WoldenHanson T. Serum and muscle interleukin-15 levels decrease in aging mice: correlation with declines in soluble interleukin-15 receptor alpha expression. Exp Gerontol. 2010;45(2):106-112.

8. Quinn LS, Haugk KL, Grabstein KH. Interleukin15: a novel anabolic cytokine for skeletal muscle. Endocrinology. 1995;136(8):3669-3672.

9. Furmanczyk PS, Quinn LS. Interleukin-15 increases myosin accretion in human skeletal myogenic cultures. Cell Biol Int. 2003;27(10):845-851.

10. Quinn LS, Anderson BG, Drivdahl RH, Alvarez B, Argiles JM. Overexpression of interleukin-15 induces skeletal muscle hypertrophy in vitro: implications for treatment of muscle wasting disorders. Exp Cell Res. 2002;280(1):55-63.

11. Pistilli EE, Alway SE. Systemic elevation of interleukin-15 in vivo promotes apoptosis in skeletal muscles of young adult and aged rats. Biochem Biophys Res Commun. 2008;373(1):20-24.

12. Carbo $N$, et al. Interleukin-15 antagonizes muscle protein waste in tumour-bearing rats. $\mathrm{Br} J$ Cancer. 2000;83(4):526-531.

13. Figueras $M$, et al. Interleukin-15 is able to suppress the increased DNA fragmentation associated with muscle wasting in tumour-bearing rats. FEBS Lett. 2004;569(1-3):201-206.

14. He Y, et al. IL-15 receptor deletion results in circadian changes of locomotor and metabolic activity. J Mol Neurosci. 2010;41(2):315-321.

15. Wu X, He Y, Hsuchou H, Kastin AJ, Rood JC, Pan W. Essential role of interleukin-15 receptor in normal anxiety behavior. Brain Behav Immun. 2010;24(8):1340-1346

16. Pistilli EE, et al. Interleukin-15 and interleukin$15 \mathrm{R}$ alpha SNPs and associations with muscle, bone, and predictors of the metabolic syndrome. Cytokine. 2008;43(1):45-53.

17. Riechman SE, Balasekaran G, Roth SM, Ferrell RE. Association of interleukin-15 protein and interleukin-15 receptor genetic variation with resistance exercise training responses. J Appl Physiol. 2004;97(6):2214-2219.

18. Di Renzo L, et al. Normal Weight Obese syndrome: role of single nucleotide polymorphism of IL-1 5Ralpha and MTHFR 677C--> T genes in the relationship between body composition and resting metabolic rate. Eur Rev Med Pharmacol Sci. 2006;10(5):235-245.

19. Di Renzo L, et al. Role of interleukin-15 receptor alpha polymorphisms in normal weight obese syndrome. Int J Immunopathol Pharmacol. 2009;22(1):105-113.

20. Nielsen AR, et al. Association between interleukin-15 and obesity: interleukin-15 as a potential regulator of fat mass. J Clin Endocrinol Metab. 2008;93(11):4486-4493.

21. Bergamaschi C, et al. Intracellular interaction of interleukin-15 with its receptor alpha during production leads to mutual stabilization and increased bioactivity. J Biol Chem. 2008;283(7):4189-4199.

22. Dubois S, Mariner J, Waldmann TA, Tagaya Y. IL-15Ralpha recycles and presents IL-15 In trans to neighboring cells. Immunity. 2002;17(5):537-547.

23. Budagian V, Bulanova E, Paus R, Bulfone-Paus S. IL-15/IL-15 receptor biology: a guided tour through an expanding universe. Cytokine Growth Factor Rev. 2006;17(4):259-280.

24. Rubinstein MP, et al. Converting IL-15 to a superagonist by binding to soluble IL-15R \{alpha\}. Proc Natl Acad Sci U S A. 2006;103(24):9166-9171.

25. Dubois S, Patel HJ, Zhang M, Waldmann TA, Muller JR. Preassociation of IL-15 with IL-15R alphaIgG1-Fc enhances its activity on proliferation of $\mathrm{NK}$ and CD8+/CD44high T cells and its antitumor action. J Immunol. 2008;180(4):2099-2106.

26. Stoklasek TA, Schluns KS, Lefrancois L. Combined
IL-15/IL-15Ralpha immunotherapy maximizes IL-15 activity in vivo. J Immunol. 2006;177(9):6072-6080.

27. Lodolce JP, et al. IL-15 receptor maintains lymphoid homeostasis by supporting lymphocyte homing and proliferation. Immunity. 1998;9(5):669-676.

28. Kennedy MK, et al. Reversible defects in natural killer and memory CD8 T cell lineages in interleukin 15-deficient mice. J Exp Med. 2000;191(5):771-780.

29. Budagian V, et al. Natural soluble interleukin-15Ralpha is generated by cleavage that involves the tumor necrosis factor-alpha-converting enzyme (TACE/ ADAM17). J Biol Chem. 2004;279(39):40368-40375.

30. Mortier E, et al. Soluble interleukin-15 receptor alpha (IL-15R alpha)-sushi as a selective and potent agonist of IL-15 action through IL-15R beta/ gamma. Hyperagonist IL-15 $\mathrm{x}$ IL-15R alpha fusion proteins. J Biol Chem. 2006;281(3):1612-1619.

31. Dubois $S$, et al. Natural splicing of exon 2 of human interleukin-15 receptor alpha-chain mRNA results in a shortened form with a distinct pattern of expression. J Biol Chem. 1999;274(38):26978-26984

32. Anderson DM, et al. Functional characterization of the human interleukin-15 receptor alpha chain and close linkage of IL15RA and IL2RA genes. $J$ Biol Chem. 1995;270(50):29862-29869.

33. Bulanova E, et al. Soluble Interleukin IL-15Ralpha is generated by alternative splicing or proteolytic cleavage and forms functional complexes with IL-15. J Biol Chem. 2007;282(18):13167-13179.

34. Quinn LS, Anderson BG, Strait-Bodey L, Stroud AM, Argiles JM. Oversecretion of interleukin-15 from skeletal muscle reduces adiposity. Am J Physiol Endocrinol Metab. 2009;296(1):E191-E202.

35. Sieck GC, Sacks RD, Blanco CE, Edgerton VR. SDH activity and cross-sectional area of muscle fibers in cat diaphragm. J Appl Physiol. 1986;60(4):1284-1292.

36. Chen ZX, Pervaiz S. Involvement of cytochrome $\mathrm{c}$ oxidase subunits $\mathrm{Va}$ and $\mathrm{Vb}$ in the regulation of cancer cell metabolism by Bcl-2. Cell Death Differ. 2009;17(3):408-420.

37. Allen DL, Roy RR, Edgerton VR. Myonuclear domains in muscle adaptation and disease. Muscle Nerve. 1999;22(10):1350-1360

38. Burleigh IG. Observations on the number of nuclei within the fibres of some red and white muscles. J Cell Sci. 1977;23:269-284

39. Van Dyke AL, Cote ML, Wenzlaff AS, Land S, Schwartz AG. Cytokine SNPs: comparison of allele frequencies by race and implications for future studies. Cytokine. 2009;46(2):236-244.

40. Chan S, Seto JT, MacArthur DG, Yang N, North $\mathrm{KN}$, Head SI. A gene for speed: contractile properties of isolated whole EDL muscle from an alphaactinin-3 knockout mouse. Am J Physiol Cell Physiol. 2008;295(4):C897-C904.

41. Lin J, et al. Transcriptional co-activator PGC-1 alpha drives the formation of slow-twitch muscle fibres. Nature. 2002;418(6899):797-801.

42. Burke RE. The structure and function of motor units. In: Engel AG, Franzini-Armstrong C, eds. Myology. 3rd ed. New York, New York, USA: McGraw-Hill; 2004:104-118.

43. Celichowski J, Grottel K. Twitch/tetanus ratio and its relation to other properties of motor units. New roreport. 1993;5(3):201-204.

44. Rassier DE, Tubman LA, MacIntosh BR. Inhibition of Ca2+ release in rat atrophied gastrocnemius muscle. Exp Physiol. 1997;82(4):665-676.

45. Mason SD, et al. Loss of skeletal muscle HIF1alpha results in altered exercise endurance. PLoS Biol. 2004;2(10):e288.

46. Narkar VA, et al. AMPK and PPARdelta agonists are exercise mimetics. Cell. 2008;134(3):405-415.

47. Fischer MD, et al. Definition of the unique human extraocular muscle allotype by expression profiling. Physiol Genomics. 2005;22(3):283-291.
48. Fischer MD, et al. Expression profiling reveals metabolic and structural components of extraocular muscles. Physiol Genomics. 2002;9(2):71-84.

49. Porter JD, et al. Extraocular muscle is defined by a fundamentally distinct gene expression profile. Proc Natl Acad Sci U S A. 2001;98(21):12062-12067.

50. Puigserver P, Spiegelman BM. Peroxisome proliferator-activated receptor-gamma coactivator 1 alpha (PGC-1 alpha): transcriptional coactivator and metabolic regulator. Endocr Rev. 2003;24(1):78-90.

51. Handschin C, et al. Skeletal muscle fiber-type switching, exercise intolerance, and myopathy in PGC-1alpha muscle-specific knock-out animals. J Biol Chem. 2007;282(41):30014-30021.

52. Leberer E, Pette D. Immunochemical quantification of sarcoplasmic reticulum Ca-ATPase, of calsequestrin and of parvalbumin in rabbit skeltal muscles of defined fiber composition. Eur J Biochem. 1986;156(3):489-496.

53. Paolini $\mathrm{C}$, et al. Reorganized stores and impaired calcium handling in skeletal muscle of mice lacking calsequestrin-1.J Physiol. 2007;583(pt 2):767-784.

54. Wu X, Pan W, Stone KP, Zhang Y, Hsuchou H, Kastin AJ. Expression and signaling of novel IL15Ralpha splicing variants in cerebral endothelial cells of the blood-brain barrier. I Neurochem. 2010;114(1):122-129.

55. Hanisch UK, et al. Mouse brain microglia express interleukin-15 and its multimeric receptor complex functionally coupled to Janus kinase activity. J Biol Chem. 1997;272(46):28853-28860.

56. Kubota T, Brown RA, Fang J, Krueger JM. Interleukin-15 and interleukin- 2 enhance non-REM sleep in rabbits. Am J Physiol Regul Integr Comp Physiol. 2001;281(3):R1004-R1012.

57. Doherty TJ. Invited review: aging and sarcopenia. J Appl Physiol. 2003;95(4):1717-1727.

58. Grounds MD, Radley HG, Lynch GS, Nagaraju K, De Luca A. Towards developing standard operating procedures for pre-clinical testing in the $\mathrm{mdx}$ mouse model of Duchenne muscular dystrophy. Neurobiol Dis. 2008;31(1):1-19.

59. Varela GM, et al. Inhibition of ADRP prevents dietinduced insulin resistance. Am J Physiol Gastrointest Liver Physiol. 2008;295(3):G621-G628.

60. Wong T, Hildebrandt MA, Thrasher SM, Appleton JA, Ahima RS, Wu GD. Divergent metabolic adaptations to intestinal parasitic nematode infection in mice susceptible or resistant to obesity. Gastroenterology. 2007;133(6):1979-1988.

61. Pistilli EE, et al. Targeting the Activin Type IIB Receptor to Improve Muscle Mass and Function in the $\mathrm{mdx}$ Mouse Model of Duchenne Muscular Dystrophy. Am J Pathol. 2011;178(3):1287-1297.

62. Burke RE, Levine DN, Tsairis P, Zajac FE 3rd. Physiological types and histochemical profiles in motor units of the cat gastrocnemius. J Physiol. 1973;234(3):723-748

63. Brooks SV, Faulkner JA. Contractile properties of skeletal muscles from young, adult and aged mice. JPhysiol. 1988;404:71-82.

64. Lynch GS, Hinkle RT, Chamberlain JS, Brooks SV, Faulkner JA. Force and power output of fast and slow skeletal muscles from mdx mice 6-28 months old. J Physiol. 2001;535(pt 2):591-600.

65. Degens H, Turek Z, Hoofd LJ, Van't Hof MA, Binkhorst RA. The relationship between capillarisation and fibre types during compensatory hypertrophy of the plantaris muscle in the rat. $J$ Anat. 1992;180(pt 3):455-463.

66. Yang N, et al. ACTN3 genotype is associated with human elite athletic performance. Am J Hum Genet. 2003;73(3):627-631.

67. Huttley GA, Wilson SR. Testing for concordant equilibria between population samples. Genetics. 2000;156(4):2127-2135 